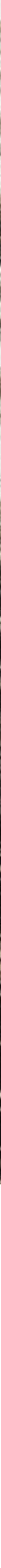




\section{Résumés des Publications du CIFOR en 1997}




\section{Le réseau CGIAR}

Le groupe consultatif pour la recherche agricole internationale (CGIAR) est une association libre de donateurs des secteurs publics et privés, créée en 1971. Il appuie un réseau de 16 instituts internationaux de recherche agricole, dont le dernier en date est le CIFOR. Les Centres CGIAR constituent un réseau mondial de recherche agricole qui met à contribution les capacités scientifiques internationales pour trouver des solutions aux problèmes des populations défavorisées du globe.

\section{CIFOR}

Le centre de recherche forestière internationale (CIFOR) est un institut de recherche international indépendant, dont le rôle est de mettre la science au service des forêts tropicales et des populations qui y vivent. CIFOR a été créé en 1993 par le CGIAR en réponse aux préoccupations mondiales sur les conséquences sociales, écologiques et économiques de la destruction et de la dégradation des forêts. Il agit en partenariat décentralisé avec des institutions ou des chercheurs, tant dans les pays en développement que dans les pays industrialisés, avec les administrations nationales, les universités, les ONG et les instituts de recherche du secteur privé ou para-publique. La nature et la durée de ces partenariats dépendent des problèmes de recherche particuliers à traiter. Le programme de recherche est révisé périodiquement en prenant en compte les facteurs de changement et l'émergence de circonstances nouvelles.

Le Centre de Recherche Forestière Internationale Bogor, Indonésie 


\section{Contenu}

1. Liste des auteurs V

2. Publications du CIFOR en 1997 (Publications internes) 1

3. Publications des Chercheurs du CIFOR en 1997 (Publications externes) 


\section{Liste des Auteurs}

\section{A}

Angelsen, A.

'La thèse pauvreté-environnement: Brundtland s'est-elle trompée ?

\section{B}

Bertault, J.-G. et Sist, P.

Comparaison expérimentale de différentes intensités de coupe avec des méthodes d'exploitation classiques et à faible impact au Kalimantan oriental.

Boyle, Timothy J.B. et Boontawee, Boonchoob (sous la direction de)

Mesure et suivi de la biodiversité dans les forêts tropicales et tempérées.

Boyle, T.J.B., Cossalter, C.C. et Griffin, A.R.

Ressources génétiques pour le reboisement.

Brown, A.G., Nambiar, E.K.S. et Cossalter, C.C.

Plantations forestières tropicales - leur rôle, leur étendue et leur nature.

Brown, A.G., Turnbull, J.W. et Booth, T.H.

Le milieu Australien.

Byron, $N$.

Problèmes et solutions possibles: choix d'orientations pour le secteur forestier dans la région Asie-Pacifique.

Byron, $N$.

Assistance internationale au développement en matière de forêts et d'aménagement des terres: le processus et les acteurs.

\section{CATIE et CIFOR}

Aménagement des forêts feuillus naturelles en Amérique tropicale: bibliographie.

Colfer, C.J. Pierce et Dudley, R.G.

Cultivateurs itinérants en Indonésie: maraudeurs ou gestionaires de la forêt : Production de riz et utilisation de la forêt par les Uma' Jalan de Kalimantan Est..

Colfer, C.J. Pierce with Peluso, N.L. et Chin See Chung

Au delà de la culture sur brûlis: s'appuyer sur la science autochtone pour aménager les forêts denses de Bornéo. 
Colfer, C.J. Pierce, Wadley, R.L., Woelfel, J. et Harwell, E.

De l'écorce au bois de cœur: la place des femmes dans l'aménagement forestier

Colfer, C.J. Pierce, Wadley, R.L. Woelfel, J. et Harwell, E.

Du bois de cœur à l'écorce en Indonésie: la femme et l'aménagement forestier.

D

Doran, J.C. et Turnbull, J.W. (sous la direction de)

Arbres et arbustes australiens pour la restauration des sols et les plantations fermières dans les tropiques.

Doran, J.C., Turnbull, J.W. Martensz, P.N., Thomson, L.A.J. et Hall, N.

Introduction aux condensés sur les espèces.

de Jong, $W$.

Le développement de l'agriculture itinérante et la menace de perte de biodiversité.

Dykstra, D. P. (sous la direction de)

Exploitation forestière et conservation des forêts dans les tropiques.

Dykstra, D. P.

Contexte historique et cadre conceptuel du code modèle d'exploitation forestière de la FAO.

Dykstra, D. P.

Systèmes d'information appliqués à la foresterie.

Dykstra, D. P. et Heinrich, R.

Récolte et transport des produits forestiers: problèmes anciens, solutions nouvelles.

Dykstra, D. P., Kowero, G. S., Ofosu-Asiedu, A. et Kio, P.

Promotion de l'aménagement forestier dans la zone de forêt tropicale humide d'Afrique occidentale et Centrale Anglophone.

F

FAO, IUFRO, et CIFOR

Nouvelles dispositions pour les sciences forestières. 
Favrichon, V., Dupuy, B., Maitre, H. F., Nguyen-The, N., Damio, T., Doumbia, N., Kadir, K., Petrucci, Y. et Sist, P.

Réponse des peuplements forestiers tropicaux aux interventions sylvicoles.

G

Gillison, A.N.

Cartographie de la distribution potentielle des espèces végétales et animales en vue de l'aménagement de la faune sauvage: emploi du programme informatique DOMAIN.

Gillison, A.N. et Carpenter, G.

Emploi d'un jeu d'attributs fonctionnels des plantes et d'une syntaxe pour la description et l'analyse dynamiques de la végétation.

Gillison, A.N., Schulze, W., Schulze, E.D. et Pate, J.S.

Alimentation azotée à partir du sol et des insectes au cours de la croissance des plantes insectivores Nepenthes mirabilis, Cephalotus follicaris et Darlingtonia californica

Gluck, P., Tarasofsky, R., Byron, N. et Tikkanen, I.

Mesures possibles pour renforcer la juridiction internationale concernant les forêts.

Goloubinoff, M., Katz, E. et Lammel, A. (sous la direction de)

Anthropologie du climat dans le monde hispano-américain.

Gregersen, H., Lundgren, A., Kengen, S. et Byron, N.

Mesure et prise en compte des valeurs de la forêt pour la prise de décisions.

Guariguata, M.R. et Dupuy, J.M.

Régénération forestière sur les pistes de débardage abandonnées dans les forêts de plaine du Costa Rica.

Guariguata, M.R., Chazdon, R.L., Denslow J.S., Dupuy, J.M. et Anderson, L. Structure et composition floristique des forêts secondaires et des vieilles forêts de plaine du Costa Rica.

\section{H}

Hartati, N. S., Sudarmonowati, E., Fahdiar, A. et Siregar, U. J.

Détection de la variation d'isozyme chez quatre espèces d'arbres fruitiers (Garcinia mangostana, Parkia javanica, Nephelium lappaceum et Artocarpus heterophyllus) en utilisant les techniques d'électropohorèse a base de gel d'amidon 
Ibach, Michael et Byron, Yvonne (sous la direction de)

Compte rendu d'un forum de discussion sur les Services d'information dans la région Asie-Pacifique et AGRIS/CARIS au 21ème siècle consultation régionale Asie-Pacifique

\section{$\mathbf{K}$}

Katz, E.

Un siècle de culture de caféiers. Dynamique des agroécosystèmes de caféières dans la région des Mixtèques, Mexique

Katz, E.

Les produits forestiers autres que le bois dans la région de Bulungan, Kalimantan oriental, Indonésie.

Katz, E.

Conférence régionale pour l'Afrique sur la conservation, l'aménagement et l'utilisation des plantes fournissant des gommes, des résines et des huiles essentielles.

Katz, E.

Rites, représentations et météorologie dans la Terre de la pluie, Mixteca, Mexique.

Katz, E. and Nguinguiri, J. C.

Les stratégies territoriales face à l'etat: un exemple d'appropriation de l'espace au Kouilou (Congo)

Kaimowitz, D.

Facteurs déterminant un faible taux de déboisement: enseignements tirés de l'Amazonie bolivienne.

Kaimowitz, D.

Les progrès de l'agriculture permanente en Amérique Latine.

Kaimowitz, D.

Modes d'utilisation des terres et gestion des ressources naturelles en Amérique Centrale.

Kaimowitz, D.

Politiques influant sur la déboisement en vue de l'élevage en Amérique Centrale.

Kiekens, J. P. et Byron, R. N. 
Coopération forestière internationale: quelle voie adopter maintenant?

Kiker, C. F. et Putz, F. E.

La certification écologique des produits forestiers: problèmes économiques.

Kowero, G.S. et Spilsbury, M.J.

Evaluation de la capacité de recherche forestière en Afrique Orientale et Australe.

Kowero, G.S. et Spilsbury, M.J.

Capacités en matière de recherche forestière dans la Communauté de développement de l'Afrique Australe.

\section{M}

Maogong, Z., Maoyi, F., Belcher, B., et Ruiz-Perez, M.

Influence des facteurs socio-économiques et des politiques sociales sur les systèmes de gestion de la production - Etude de cas dans l'industrie du bambou en Chine.

Midgley, S.J., Byron, R.N., Chandler, F.C., Ha Huy Thinh, Tran Vo Hung Son et Hoang Hong Hanh.

Les plantes ont-elles besoin de passeports? Etude socio-économique sur le rôle des arbres et autres plantes exotiques dans la province de Quang Tri au Vietnam.

Mittelman, A.J., Lai, C.K., Byron, N, Michon, G. et Katz, E.

Etude de prospective sur les produits forestiers autres que le bois dans la région Asie-Pacifique à l'horizon 2010.

Nasi, $R$.

Les peuplements d'Okoumés au Gabon

Ndoye, O. et Ruiz-Pérez, $M$.

Les marchés pour les produits forestiers autres que le bois dans la zone de forêt dense du Cameroun.

Ndoye, O., Ruiz Pérez, M. et Eyebe, A.

Les marchés pour les produits forestiers autres que le bois dans la zone de forêt dense du Cameroun.

Nhantumbo, I., Dent, J.B., Kowero, G.S. et McGregor, M.J.

Bénéfices non commerciaux des forêts: méthode de modélisation pour l'orientation des interventions au Mozambique. 


\section{O}

Old, K.M., See, Su Lee et Sharma, J.K.

Maladies des acacias tropicaux

Oreshkin, D.G., Skovsgaard, J.P. et Vanclay, J.K.

Estimation de la vitalité des gaulis de pin sylvestre, Pinus sylvestris, en

Carélie russ.

$\mathbf{P}$

Paine, J.R., Byron, N. et Poffenberger, M.

Situation, tendances et scénarios futurs pour la conservation des forêts, notamment des aires protégées, dans la région Asie-Pacifique.

Parrotta, J.A., Turnbull, J.W. et Jones, N.

Catalyser la régénération des forêts naturelles sur les terres tropicales dégradées

Persson, R. et Janz, $K$.

Evaluation et suivi des ressources de forêts et d'arbres

Pinard, M. A. et Putz, F. E.

Observation suivie des gains en fixation du carbone associés à un projet d'exploitation forestière à faible impact en Malaisie

Prabhu, R. et Vanclay, J. K.

Arrêter une cible mobile: production soutenue, population et forêts

Putz, F. E. , Elias, Sist, P., Dykstra, D. P. et Heinrich, R.

Méthodes de recherche pour l'exploitation forestière à faible impact: résultats d'un colloque.

\section{$\mathbf{R}$}

Ruiz-Pérez, M et Arnold, J.E.M.(sous la direction de)

Questions d'actualité en matière de recherche sur les produits forestiers autres que le bois.

Sabogal, C., Camacho, M. and Guariguata, M. (sous la direction de)

Expériences pratiques et priorités de recherche en sylviculture des forêts naturelles en Amérique tropicale. 
Saxena, N.C.

La saga de la gestion forestière participative en Inde.

Sayer, J.A., Vanclay, J.K. et Byron, N.

Techniques pour répondre aux enjeux de l'aménagement des forêts au

21ème siècle.

Segura, O., Kaimowitz, D. et Rodríguez, J. (sous la direction de)

Politiques forestières en Amérique Centrale: analyse des contraintes au développement du secteur forestier

Sist, P. et Bertault, J.G.

Le projet STREK

Skovsgaard, J.P. et Vanclay, J.K.

Succès de la régénération et croissance intiale des peuplements forestiers.

Smith, J., Sabogal, C., de Jong, W. et Kaimowitz, D.

Les forêts secondaires, ressource pour le développement rural et la conservation de l'environnement en Amérique Latine tropicale.

Sudarmonowati, E., Hartati, N. S. et Siregar, U. J.

Mise au point de techniques de marqueurs génétiques biochimiques pour Shorea spp et autres essences forestières tropicales

Sunderlin, W. D.

Déboisement, moyens de subsistance et conditions préalables de l'aménagement forestier dans le département d'Olancho, Honduras

Sunderlin, W.D.

Méthologie pour la mesure a posteriori de la participation des populations pauvres à la foresterie sociale: un exemple de Java, Indonésie

Sunderlin, W.D.

Culture itinérante et déboisement en Indonésie: comment éviter la confusion dans les discussions

Sunderlin, W.D. et Gorospe, M.L.G.

Organisations de pêcheurs et modes de cogestion: le cas de la baie de

San Miguel aux Philippines

Sunderlin, W.D. et Resosudarmo, Ida Aju

Taux et causes de la déforestation en Indonésie: Vers une résolution des ambiguités 
Tomich, T.P., Kuusipalo, J., Menz, K. et Byron, N.

Une économie et une politique pour Imperata

Turnbull, J.W.

La végétation de l'Australie

Turnbull, J.W. et Awang, K.

Acacia auriculiformis

Turnbull, J. W. et Byron, R. N.

Plantations forestières tropicales en vue de productions de haute valeur: étude de perspective du CIFOR

Turnbull, J.W. et Doran, J.C. Eucalyptus urophylla

V

Vanclay, J.K.

Changements et enjeux pour la foresterie internationale: préparer le 21ème siècle.

Vanclay, J.K.

FLORES: un modèle pour évaluer les choix de mise en valeur des terres en lisière de forêt

Vanclay, J.K.

Tirer le maximum de profit des données de parcelles permanentes.

Vanclay, J.K.

Introduction à la prévision de rendement de la forêt

Vanclay, J.K.

Pour une évaluation plus rigoureuse de la biodiversité

Vanclay, J.K.

TROPIS, Système d'information sur la croissance des arbres et les parcelles permanentes

Vanclay, J.K. et Skovsgaard, J.P.

Evaluation des modèles de croissance des peuplements forestiers

Vanclay, J.K., Gillison, A.N. et Keenan, R.N.

Utilisation des attributs fonctionnels des plantes pour l'évaluation de la productivité de la station et des modes de croissance dans les forêts mélangées 
Wily, Liz

Trouver un cadre institutionnel et juridique approprié pour la gestion communautaire des forêts naturelles: le cas de la Tanzanie.

Waldley, R.L., Colfer, C.J. Pierce et Hood, I.G.

Chasse des primates et aménagement forestier: le cas des agriculteurs forestiers Iban au Kalimantan oriental, Indonésie

Wibowo, D.H. et Byron, R.N.

Mécanismes du déboisement: résultats d'une enquête

Wibowo, D.H., Tisdell, C.A. et Byron, R.N.

Déboisement et accumulation de capital: leçons tirées de la région du

Haut Kerinci, Indonésie

Wollenberg, E.

Prise de décisions entre intérêts divers: emploi de scénarios d'avenir pour orienter la gestion locale des forêts - proposition de méthodologie

Wollenberg, E. et Colfer, C.J.P.

Stabilité sociale.

$\mathbf{Z}$

Zuidema Pieter a., Sayer A. Jeffrey et Dijkman Wim

Morcellement des forêts et biodiversité: arguments en faveur d'aires de conservation de taille intermédiaire. 
Mesure et suivi de la biodiversité dans les forêts tropicales et tempérées.

Boyle, Timothy J.B. et Boontawee, Boonchoob (sous la direction de)

De nombreux chercheurs estiment que les forêts mondiales renferment plus de $50 \%$ de la biodiversité terrestre. Or les forêts tempérées et les forêts tropicales sont en butte à de nombreuses menaces, notamment du fait de l'expansion de l'agriculture et de l'industrie, des changements climatiques, d'une mauvaise gestion des ressources, et de la pollution. Si l'on veut conserver les forêts et la diversité des organismes vivants qu'elles hébergent, il faut mesurer et observer de manière suivie leur biodiversité, afin de pouvoir estimer l'impact des activités humaines et l'efficacité des mesures de conservation. Etant donné que le concept de biodiversité couvre tous les aspects qui concernent la vie, depuis les gènes jusqu'aux écosystèmes, cette mesure et ce suivi sont extrêmement complexes.

Cet ouvrage contient 24 articles sélectionnés parmi les communications présentées à un colloque de l'IUFRO sur le sujet "Mesure et suivi de la biodiversité dans les forêts tropicales et tempérées", qui s'est tenu du 27 août au 2 septembre 1994 au Département royal des forêts de Thaïlande à Chiang Mai. Les articles ont été choisis de manière à couvrir le plus largement possible des sujets généraux importants: Principes de la mesure et du suivi de la biodiversité ( 8 articles), Diversité génétique (6 articles), Diversité des espèces et des écosystèmes ( 5 articles), Méthodologie ( 5 articles). Les arbres forestiers font le sujet de plusieurs articles, mais on y trouve également des articles traitant de la diversité des arthropodes, des champignons microscopiques, des oiseaux et des papillons, des gibbons, et d'autres traitant de tout l'ensemble de la biodiversité.

1995, 240 p., $10 \$ E U$ (2ème tirage)

ISBN 979-8764-01-3

Nouvelles dispositions pour les sciences forestières. FAO, IUFRO et CIFOR

A mesure que les chercheurs forestiers élargissent leur champ de vision et considèrent les problèmes d'un point de vue multi-sectoriel et dans une perspective historique, ils commencent à poser davantage de questions pressantes, et à y répondre. S'ils adoptent une approche analytique plutôt que descriptive, ils feront de nombreuses nouvelles découvertes. La 
nouvelle ambiance générale dans laquelle doit maintenant opérer la recherche forestière reflète une préoccupation croissante des changements qui interviennent localement et mondialement dans notre environnement, et de la nécessité de les maîtriser par la poursuite d'un développement durable. Le fond du problème est de réaliser un équilibre entre les besoins de tous les peuples, et de reconnaître que des changements dans la santé de la forêt ont de multiples répercussions sur l'environnement tant local que mondial. Les forêts sont un élément essentiel de l'interface entre l'homme et la nature. On ne peut plus les étudier comme si elles étaient de simples "usines de plein air pour produire du bois", en dehors de la société, et que les activités forestières n'aient qu'un intérêt local. Dans le monde réel, les forêts jouent un rôle fondamental dans la société, et peuvent exercer des influences à tous les niveaux. A mesure que les chercheurs forestiers, et d'autres, tiendront compte de ce fait, le monde prendra conscience de l'importance véritable des forêts et de leur rôle central dans le développement durable.

L'IUFRO, la FAO et le CIFOR présentent collectivement une proposition - encourageante - en vue de classer les recherches forestières selon les priorités réelles des usagers, et d'y répondre en conséquence.

Document de discussion établi en vue de la Quatrième réunion du Comité intergouvernemental sur les forêts, New York, février 1997, 17p.

Compte rendu d'un forum de discussion sur les Services d'information dans la région Asie-Pacifique et AGRIS/CARIS au 21ème siècle - consultation régionale Asie-Pacifique.

Ibach, Michael et Byron, Yvonne (sous la direction de)

L'information disponible pour les chercheurs dans le monde d'aujourd'hui, et les techniques qui permettent d'y accéder et de l'utiliser, connaissent une expansion rapide. Malheureusement, la plupart des organismes forestiers et des instituts de recherche forestière de la région Asie-Pacifique n'ont pas accès à la grande masse d'information existante et ne sont pas en mesure de l'utiliser efficacement pour la prise de décisions.

Un certain nombre d'organismes de la région ont des objectifs communs de développement de leurs capacités dans le domaine de la recherche forestière. C'est pour y répondre que des représentants du Projet 
de Centre de semences forestières de l'ANASE (AFTSC), de l'Institut d'aménagement forestier de l'ANASE (AIFM), du Centre de recherche forestière internationale (CIFOR), du Centre de recherches pour le développement international (CRDI), des Offices agricoles du Commonwealth (CABI), et du Programme d'appui à la recherche forestière pour l'Asie et le Pacifique (FORSPA), ont proposé des solutions passant par des activités en coopération.

Ce document est le compte rendu d'un forum de discussion sur les services d'information dans la région Asie-Pacifique, qui s'est tenu du 30 octobre au 1er novembre 1996 à Bogor (Indonésie). Un inventaire des besoins perçus, établi par une enquête préliminaire, a servi de guide aux discussions du forum. Les participants ont défini des objectifs prioritaires et des plans d'action pour les réaliser, désigné les personnes et organismes responsables, et proposé des calendriers d'exécution et des coûts probables.

Le Système intégré d'information pour les sciences et la technologie agricoles (AGRIS) et le Système d'information sur les recherches agronomiques en cours (CARIS) sont des éléments du réseau général de la FAO fournissant une base mondiale d'information sur la recherche agricole et questions connexes. Pour examiner la question d'AGRIS-CARIS au 21ème siècle, une consultation régionale Asie-Pacifique s'est tenue conjointement avec le forum de discussion. Le présent document rapporte les discussions portant sur l'intensification des activités en coopération et le développement de nouvelles approches en vue d'améliorer la couverture de la littérature forestière dans AGRIS et de l'information sur la recherche forestière dans CARIS parmi les pays de la région Asie-Pacifique, ainsi que sur l'examen des progrès récents en matière de techniques de l'information et de leurs impacts sur les pourvoyeurs et utilisateurs d'information. Un examen détaillé indépendant a été recommandé pour évaluer AGRIS et CARIS et leurs futures orientations au siècle prochain, plus particulièrement en ce qui concerne l'information sur la forêt.

Document Occasionnel No. 10, 1997, 106p. 
Capacités en matière de recherche forestière dans la Communauté de développement de l'Afrique Australe.

Kowero, G.S. et Spilsbury, M.J.

Une enquête a été effectuée en 1995 sur les capacités de recherche d'institutions menant des recherches forestières dans les pays de la Communauté de développement de l'Afrique australe (SADC). Ce document passe en revue les méthodes disponibles pour évaluer les capacités en matière de recherche, et résume les efforts entrepris précédemment pour évaluer ces capacités dans la région.

La méthodologie adoptée fait appel à des indicateurs communs, ce qui permet des comparaisons entre institutions. Les résultats de l'enquête sont discutés, et ils font ressortir à nouveau la nécessité de donner priorité au recrutement, à la formation et au perfectionnement de personnels de recherche; la moitié seulement des chercheurs travaillant sur des questions de recherche forestière et connexes ont une formation et une expérience scientifiques suffisantes. La gestion de la recherche est un autre domaine qui demande d'urgence une attention afin de neutraliser dans la mesure du possible les effets négatifs des facteurs économiques et autres dont souffre la recherche dans la région. Seulement $17 \%$ et $28 \%$ des institutions enquêtées consacrent plus de $20 \%$ de leur budget et du temps de travail de leur personnel, respectivement, à des groupes d'usagers. Cela soulève des questions sur la manière dont les priorités de recherche sont formulées et sur l'opportunité des recherches en cours. Il y a une collaboration active entre institutions de la région, mais on ne voit pas clairement comment elle peut se traduire dans la réalité en actions concertées.

La méthodologie pour l'évaluation de la capacité de recherche est également présentée. Bien que les indicateurs pour les divers paramètres de capacité de recherche ne couvrent pas l'intégralité de cette capacité dans tous les domaines, ils fournissent un aperçu utile de la capacité locale d'entreprendre des recherches forestières en Afrique orientale et australe.

Document Occasionnel No. 11, 1997, 45p 
Maladies des acacias tropicaux.

Old, K.M., See, Sue Lee et Sharma, J.K.

Les acacias ont une importance sociale et industrielle considérable pour le reboisement dans les tropiques, et l'on prévoit qu'en l'an 2000 il y en aura quelque 2 millions d'hectares dans le Sud-Est asiatique. Les acacias les plus intéressants actuellement pour les reboisements tropicaux sont originaires d'Australie, de Papouasie-Nouvelle-Guinée et d'Irian Jaya.

De récents rapports en provenance de Malaisie, d'Indonésie, de Thaïlande et du nord de l'Australie indiquent que la productivité future des plantations d'acacias risque d'être compromise par des maladies cryptogamiques telles que rouille des feuilles, anthracnose des pousses, chancre du tronc, pourriture du cœur, pourriture des racines et galles fongiques. En 1995-1996 une série de prospections ont été entreprises par des pathologistes forestiers dans des peuplements naturels, des essais, des reboisements industriels et des plantations sociales d'acacias tropicaux en Australie, en Inde, en Indonésie, en Malaisie et en Thaïlande en vue d'évaluer le rôle potentiel des champignons pathogènes en tant que facteurs limitants de la croissance et de la productivité des arbres et l'importance relative de chacun d'eux. Les espèces incluses dans ces études étaient Acacia mangium et A. auriculiformis, en raison de leur importance actuelle comme essences de reboisement, ainsi qu'A. crassicarpa et A. aulacocarpa qui, bien que n'étant plantées jusqu'à ce jour qu'à une échelle limitée, sont incluses dans des essais de provenances et d'espèces en de nombreux endroits dans toute la région. Les chercheurs qui avaient participé au projet ont rencontré des directeurs de recherche de cinq grandes sociétés privées et étatiques indonésiennes de plantations pour la production de pâte du 28 avril au 3 mai 1996 au camp de base de la PT Musi Hutan Persada Subanjeriji dans le sud de Sumatra, pour leur présenter les résultats de leurs enquêtes. La présente publication rapporte l'état de la situation concernant les maladies des acacias dans les différents pays prospectés, à partir de l'information présentée à ce colloque. Elle fait le point des connaissances actuelles sur la pathologie des quatre principales espèces d'acacias actuellement utilisées en reboisement dans les zones tropicales du Sud-Est asiatique, du souscontinent indien et du nord de l'Australie.

Les enquêtes et le colloque ont été rendus possibles grâce à un 
financement du Centre australien de recherche agricole internationale (ACIAR) et du Centre de la recherche forestière internationale (CIFOR), et à l'appui des organisations des chercheurs participants.

Publication Spéciale, 1997, 120p. ISBN 979-8764-13-7

\section{Questions d'actualité en matière de recherche sur les produits forestiers autres que le bois.}

Ruiz-Pérez, M. et Arnold, J.E.M. (sous la direction de)

Cet ouvrage présente un certain nombre de documents de base commandés pour le colloque sur la "Recherche sur les produits forestiers autres que le bois" (Hot Springs, Zimbabwe, 28 août - 2 septembre 1995). Rassemblant les expériences de différentes régions et de différentes branches professsionnelles, il cherche à analyser la complexité des usages multiples des forêts dans une perspective multidimensionnelle incorporant les facteurs écologiques, sociaux, économiques, technologiques, politiques, historiques et culturels.

Les sujets actuels de discussion sont passés en revue. On y trouve la possibilité d'accorder les programmes de conservation et de développement en encourageant l'exploitation des produits autres que le bois comme le proposent diverses initiatives, le cheminement unidirectionnel de la mise en valeur depuis l'exploitation forestière jusqu'à la production agricole intensive, le rôle des produits forestiers autres que le bois dans les stratégies de subsistance des populations, la différenciation interne entre les communautés, les différentes formes d'actions adoptées pour s'assurer la possession des terres et leurs effets divergents, ainsi que la signification et la commodité de l'utilisation des produits forestiers autres que le bois comme catégorie analytique.

Une conclusion générale à tirer de cet ouvrage est la nécessité de mettre sur pied un programme de recherche interdisciplinaire, ainsi que d'employer plus d'une approche ou méthode dans l'étude des situations complexes qui caractérisent l'utilisation multiple des forêts. 


\section{La saga de la gestion forestière participative en Inde.}

Saxena, N.C.

Après un siècle de contrôle exclusif de l'Etat, les forêts indiennes sont maintenant de plus en plus gérées avec la participation de la population. Presque tous les Etats de l'Inde ont adopté des résolutions habilitantes qui facilitent l'application du programme dit de "gestion forestière conjointe" (Joint Forest Management - JFM). Jusqu'à ce jour, cependant, cette application a été inégale. Les fonctionnaires responsables sont souvent réticents à partager leur pouvoir et leur autorité avec la population, tout en attendant d'elle qu'elle protège les forêts sans être rémunérée. On ne sait pas non plus très bien dans quelles conditions cette gestion conjointe fonctionne avec succès, ni si ces conditions sont de nature interne ou plutôt influencées par les politiques gouvernementales.

S'appuyant sur des visites répétées dans des villages "JFM" de plusieurs Etats de l'Inde, l'auteur présente une critique des politiques passées et actuelles, examine l'application de la gestion forestière participative dans cinq Etats, explique pourquoi l'action communautaire se poursuit dans le temps, et enfin expose ses conclusions dans le cadre de la théorie générale des régimes de propriété.

Cet ouvrage tente de faire une synthèse d'expériences diverses de participation, et relie les hypothèses d'action collective à la réalité empirique. C'est l'un des premiers ouvrages de référence pour la gestion forestière participative, et il sera utile pour les organismes donateurs, les gouvernements des Etats, les organes de décision et les chercheurs des programmes de développement participatif.

Publication Spéciale, 1997, 214p.

ISBN 979-8674-15-3

Techniques pour répondre aux enjeux de l'aménagement des forêts au 21ème siècle.

Sayer, J.A., Vanclay, J.K. et Byron, N.

La technique aidera à répondre aux enjeux de l'aménagement forestier au 21 ème siècle. Certains de ces enjeux comporteront le passage de l'exploitation des forêts naturelles à des plantations artificielles là où elles 
auront un avantage comparatif, une transformation plus efficace des bois moins dépendante des caractéristiques de la matière première, une demande accrue, de meilleures techniques d'information pour aider la prise de décisions, et des formules plus variées pour la conservation de la biodiversité. La définition de l'aménagement durable variera dans le temps et dans l'espace à mesure de l'évolution des espérances et aspirations de la société, de sorte qu'il n'y a pas de "formule magique" pour assurer la pérennité de la forêt. Cependant, le progrès dans cette voie pourra être facilité par une approche systématique de l'aménagement forestier englobant le cycle habituel de planification: formulation des objectifs, définition d'une stratégie, planification, exécution, contrôle et réévaluation. Cela demande une bonne compréhension de chaque situation particulière. Les aménagistes doivent disposer d'une bonne évaluation des ressources et de systèmes d'appui à la décision; ils doivent favoriser la participation de tous les ayants droit aux décisions et aux coûts et bénéfices, et mettre en place des procédures efficaces pour résoudre les conflits. Dans un système approprié, des progrès techniques tels que de meilleurs équipements mécaniques et de nouveaux instruments peuvent apporter une certaine amélioration, mais ils ne sauraient à eux seuls assurer la durabilité de l'aménagement. Les techniques d'aménagement importantes à cet égard sont celles qui favorisent une meilleure communication entre les parties prenantes et qui permettent de prendre des décisions informées prenant en compte tous les facteurs depuis les gènes jusqu'à l'écosystème. Cela reste un enjeu important pour les gestionnaires forestiers dans leur quête du rendement soutenu de leurs forêts.

Document Occasionnel No. 12, 1997, 11p.

Les forêts secondaires, ressource pour le développement rural
et la conservation de l'environnement en Amérique Latine
tropicale.

Smith, J., Sabogal, C., de Jong, W. et Kaimowitz, D.

Des données récentes montrent que la destruction des forêts primaires s'accompagne d'une expansion des forêts secondaires. Les études réalisées montrent d'autre part que les forêts secondaires sont susceptibles de fournir certains des services économiques et écologiques des forêts primaires. Cette constatation a conduit à adopter une nouvelle stratégie pour valoriser les 
forêts secondaires aux yeux des agriculteurs et des éleveurs, dans le but de les inciter à conserver indéfiniment ces forêts, ou pour le moins à retarder leur conversion à d'autres utilisations. L'objet de la présente étude est de contribuer à la définition d'une stratégie cohérente pour réaliser les potentialités des forêts secondaires. Notre hypothèse est qu'il existe de vastes surfaces de forêt secondaire dans des terrains de petits et grands producteurs, et que par des interventions techniques et une politique appropriée on pourrait accroitre notablement la surface et la valeur économique et écologique des forêts secondaires, et par conséquent la durée pendant laquelle elles seront conservées. Nous formulons en même temps l'hypothèse que les forêts secondaires présentent une grande diversité dans leurs caractéristiques écologiques ainsi que dans les objectifs et les ressources de leurs propriétaires. C'est pourquoi il est probable que les interventions requises seront éminemment variables. Une analyse de la dynamique des forêts secondaires pourra aider à orienter les interventions vers celles où elles auront le plus de chances d'avoir de l'effet. L'analyse des aspects socioéconomiques de la dynamique des forêts secondaires s'appuie sur les changements progressifs dans le temps de certaines caractéristiques des zones de frontière agricole. Nous faisons une distinction entre deux trajectoires différentes: celle suivie par les colons, et celle des communautés autochtones. Une troisième catégorie de circonstances accidentelles, telles que conflits militaires et litiges, peut également conduire à la création de forêts secondaires.

Les modes de gestion des forêts secondaires peuvent être classés en fonction des ressources qu'ils exigent (capital, terre, main-d'œuvre et capacité de gestion) et du délai nécessaire pour obtenir une production, ce qui donne quatre groupes: jachères améliorées de courte durée, jachères enrichies de moyenne durée, forêts de production à moyenne ou longue révolution, forêts de conservation. Les caractéristiques de chaque catégorie de producteurs et de forêts secondaires sont très différentes des caractéristiques des modes d'aménagement dont la probabilité d'adoption est la plus élevée.

Ensuite sont définies les catégories générales d'interventions sur les politiques appropriées à chaque catégorie de producteurs, à savoir: politiques relatives à la commercialisation des produits de la forêt secondaire, réformes de la législation et des politiques permettant aux 
producteurs de recueillir le fruit des services écologiques fournis par les forêts secondaires.

Nous concluons en soulignant l'importance d'un cadre conceptuel dynamique pour l'élaboration d'une stratégie pour les forêts secondaires, qui permettra de prévenir la dégradation de cette ressource plutôt que d'y remédier une fois qu'elle s'est produite. Le cadre conceptuel présenté permet d'autre part d'analyser les forêts secondaires en tant que partie intégrante du système de production de l'agriculteur. Enfin, on souligne que la principale contribution apportée par cette étude est le cadre conceptuel. Les résultats sont purement indicatifs, et devront être vérifiés avec des données empiriques.

Document Occasionnel No. 13 (Espagnol), 1997, 30p.

Taux et causes de la déforestation en Indonésie: Vers une résolution des ambiguités

Sunderlin, W.D. et Resosudarmo, Ida Aju

Au cours des dernières annèes l'estimation de l'importance et des causes de la déforestation en Indonésie a fait l'objet de diverses recherches sans que ces études aient pu conduire à un réel consensus au sein de la communauté scientifique. Ce document passe en revue les zones d'ombre et les étapes à franchir pour prétendre à une meilleure compréhension du sujet. Les questions clés en attente de réponse sont nombreuses. Citons par exemple: Qu'entend-t-on par forêt, déforestation et agence de développement dans le contexte indonésien? Quelles sont les caractéristiques socio-économiques et les pratiques en matière d'occupation de l'espace des divers acteurs auxquels on se réferre lorsqu'on parle de "culture itinérante"? Y-at-il une forte relation de cause à effet entre augmentation des densités de population et recul du couvert forestier ou les liens entre les deux phénomènes sont -ils purement fortuits? Pourquoi certains concessions forestières sont-elles relativement bien gérées alors que beaucoup d'autres ne le sont pas? Quel a été l'impact sur la ressource forestière des restructurations macro-économiques et des fluctuations de prix des denrées de base depuis le début des années 80 ? Le document propose de nouvelles voies de recherche sur les causes de la déforestation et la manière de l'estimer. En guise de conclusion les auteurs incitent à la vigilance face à la tendance actuelle qui vise à la simplification 
en voulant rechercher des causes uniques à un phénomène en réalité complexe puisque mu par des forces socio-économiques lourdes et à forte rémanence.

Document Occasionnel No. 9 (Indonésien), 1997, 22p.

Trouver un cadre institutionnel et juridique approprié pour la gestion communautaire des forêts naturelles: le cas de la Tanzanie.

Wily, Liz

A mesure que se développe et évolue la participation des communautés locales à la gestion des forêts naturelles, la nécessité se fait plus pressante d'inscrire les droits et obligations respectives de l'Etat et des communautés dans un cadre institutionnel rationnel, imposant des obligations juridiques. C'est particulièrement vrai dans le cas où pouvoir et autorité sont redistribués.

Cette publication examine spécialement le cas de la Tanzanie, où l'on commence à désigner les communautés forestières locales comme l'autorité chargée de la gestion de certaines forêts claires, et dans certains cas même comme propriétaire. Des résultats positifs sont un argument puissant en faveur du choix de la gestion communautaire comme stratégie d'aménagement forestier. Son application a d'autre part entraîné la nécessité de trouver des mécanismes accessibles qui permettent d'asseoir juridiquement l'autorité de la communauté.

L'auteur affirme que, à cet égard, la Tanzanie est avantagée par rapport à de nombreux autres pays de l'Afrique au sud du Sahara du fait du caractère original de l'identité juridique conférée aux communautés rurales, et de la législation administrative et foncière qui attribue aux villages la maitrise de la gestion des ressources naturelles. Elle examine entre autres particularités le fait que les villages ruraux de Tanzanie sont reconnus comme un échelon normal de l'autorité étatique, doté en conséquence de certains droits et obligations, qu'ils peuvent obtenir un statut d'entreprise leur permettant entre autres de posséder et gérer des biens selon des modalités ressortissant de la compétence des tribunaux, et enfin que la loi foncière offre une version moderne et statutaire de la tenure communautaire, dans les limites et responsabilités d'une personne juridique privée. 
L'auteur présente un guide pas à pas des moyens par lesquels une communauté riveraine de la forêt peut acquérir la garde d'une forêt naturelle locale, qu'il s'agisse d'une forêt classée ou d'une forêt du domaine public, et la responsabilité de sa gestion rationnelle et de sa conservation.

Publication Spéciale, 1997, 57p. ISBN 979-8764-16-1 


\section{La thèse pauvreté-environnement: Brundtland s'est-elle trompée?.}

Angelsen, $A$.

La thèse qui lie pauvreté et environnement suppose que les pauvres sont à la fois les agents et les victimes de la dégradation de l'environnement. Même si cette thèse a pu être nécessaire pour éviter une confrontation Nord-Sud sur les problèmes d'environnement, sa validité peut être contestée. Certains soutiennent que la coexistence de la pauvreté et de la perturbation de l'environnement pourrait plus justement être considérée comme résultant de la conjonction de possibilités limitées pour certains groupes, de processus de développement inégaux, d'une distribution inéquitable des droits et des pouvoirs, et de politiques mal conduites. Dans de nombreux cas, des revenus plus élevés accroissent la pression sur l'environnement. Ce sera particulièrement le cas là où des investissements et des facteurs de production achetés servent à accroître la capacité d'exploiter les ressources naturelles, et où la pollution est en rapport avec l'emploi de combustibles fossiles.

Forum for Development Studies 1: 135-54.

\section{Comparaison expérimentale de différentes intensités de coupe avec des méthodes d'exploitation classiques et à faible impact au Kalimantan Oriental.}

Bertault, J.G. et Sist, P.

Une étude d'exploitation forestière a été réalisée en ce qui concerne les volumes de bois marchand extrait et l'impact sur le peuplement résiduel. Des techniques d'exploitation classiques et des techniques à faible impact ont été comparées à partir d'inventaires des peuplements effectués avant et après la coupe. Le volume de bois extrait était en moyenne de $87 \mathrm{~m}^{3} / \mathrm{ha}$, et le volume de bois marchand correspondant de $46 \mathrm{~m}^{3} / \mathrm{ha}$ (soit 53,7\% du volume abattu). En moyenne, les dégâts d'abattage portaient sur $40 \%$ des arbres résiduels (diamètre à hauteur d'homme $>10 \mathrm{~cm}$ ); on note un nombre sensiblement égal d'arbres blessés et d'arbres morts (respectivement $21 \%$ et $19 \%$ ). En règle générale, l'abattage provoque des blessures aux arbres, le plus souvent sur la cime, tandis que le débardage entraîne la mort d'arbres, essentiellement par arrachage. Les arbres blessés 
et tués avec une exploitation à faible impact, en revanche, sont nettement moins nombreux (30,5\%) qu'avec les méthodes classiques $(48,1 \%)$. L'étude a montré que l'impact de l'exploitation sur les arbres restants peut être considérablement réduit par une stricte supervision, en planifiant les opérations de coupes et en limitant leur intensité, qui ne doit pas excéder $80 \mathrm{~m} 3 / \mathrm{ha}$. Si ces recommandations techniques sont suivies, il est possible de réduire le dommage de $20 \%$, ce qui équivaut à environ 100 tiges/ha (diamètre $>10 \mathrm{~cm}$ ).

Forest Ecology and Management, 94:209-18

Ressources génétiques pour le reboisement. In: Nambiar, E.K.S. et Brown, A.G. (sous la direction de) Gestion du sol, des éléments nutritifs et de l'eau dans les reboisements tropicaux, 25-63.

Boyle, T.J.B., Cossalter, C.C. et Griffin, A.R.

On a utilisé un nombre relativement réduit d'essences tropicales en reboisement. Les pins et les eucalyptus représentent environ un tiers de la superficie totale de reboisements tropicaux, et les acacias sont aussi couramment utilisés. Si l'on veut utiliser rationnellement les ressources génétiques, il importe d'évaluer les contributions relatives du génotype et du milieu au phénotype, et l'amplitude relative de la variation génétique à chaque niveau de la hiérarchie génétique: espèces, provenances, et en descendant jusqu'aux arbres individuels. Les auteurs discutent l'importance de la variation quantitative et de la génétique moléculaire dans la sélection des ressources génétiques, et décrivent l'application des stratégies d'amélioration des arbres. Ils examinent différentes approches de la sélection des ressources génétiques à chaque niveau de la hiérarchie génétique, notamment en ce qui concerne la sélection pour l'efficacité de l'utilisation de l'eau et des éléments nutritifs. Si la sélection assistée par marqueurs, les tests physiologiques et la modélisation pourront être utiles dans l'avenir, les essais de terrain classiques demeurent une nécessité absolue.

ACIAR Monograph No. 43. ACIAR avec CSIRO et CIFOR, Canberra, Australie. 
Plantations forestières tropicales - leur rôle, leur étendue et leur nature). In: Nambiar, E.K.S. et Brown, A.G. (sous la direction de) Gestion du sol, des éléments nutritifs et de l'eau dans les reboisements tropicaux), 1-23.

Brown, A.G., Nambiar, E.K.S. et Cossalter, C.C.

Ce chapitre décrit le contexte dans lequel les reboisements tropicaux se développent en tant que source de bois d'œuvre et d'industrie et de combustibles ligneux. La demande mondiale pour les premiers s'accroît, mais son rythme de croissance se ralentit et est sujet aux fluctuations de l'activité économique. La dépendance vis-à-vis des combustibles ligneux est très forte dans de nombreux pays, et dans l'ensemble ne diminue pas. Les communautés et les industries recourent de plus en plus aux plantations forestières pour satisfaire cette demande. Un petit nombre d'essences ont été très largement utilisées, mais il est souhaitable d'étendre le choix disponible pour les reboiseurs, en partie pour mieux s'adapter aux divers milieux physiques et socio-économiques des pays tropicaux. La grande diversité des climats et des sols dans les tropiques se traduit par une grande variation dans le rendement des peuplements artificiels, et de nombreuses questions essentielles restent en suspens en ce qui concerne la production soutenue des reboisements tropicaux. L'expérience des régions tempérées peut fournir un guide utile tant pour la pratique que pour la recherche dans les tropiques. Les besoins de produits ligneux ne peuvent être satisfaits par les seules forêts naturelles; les reboisements offrent des perspectives avérées de plus forte productivité par unité de surface en comparaison des forêts naturelles, et les tendances dans la production forestière indiquent que même des pays riches en forêts comptent de plus en plus pour leurs approvisionnements en bois sur les plantations forestières plutôt que sur les forêts naturelles. La production à long terme dans le respect de la protection de l'environnement est un enjeu tant pour la recherche que pour la pratique forestière.

ACIAR Monograph No. 43. ACIAR avec CSIRO et CIFOR, Canberra, Australie. 
Le milieu Australien. In: J.C. Doran et Turnbull, J.W. (sous la direction de) Arbres et arbustes Australiens pour la restauration des sols et les plantations fermières dans les tropiques, 1-18.

Brown, A.G., Turnbull, J.W. et Booth, T.H.

Cet ouvrage a pour objet de fournir un texte de référence pour tous les techniciens concernés par le choix et la plantation d'arbres et arbustes dans les zones rurales des pays en développement et dans les régions tropicales de l'Australie. Ce premier chapitre a pour but de présenter une introduction aux principales caractéristiques des milieux australiens dans lesquels ont évolué ces espèces ligneuses.

L'accent est mis sur les facteurs du milieu pour lesquels on a des chances de disposer de données sur le terrain dans d'autres pays où ces essences australiennes pourraient être utilisées, ce qui facilitera la sélection initiale d'espèces en faisant appel aux homoclimes. Une telle information a une valeur de prédiction bien meilleure que l'observation de la présence naturelle des espèces, qui peut être limitée par divers facteurs tels que le feu et la concurrence, pouvant eux-mêmes changer, et qui ne donne aucune indication sur l'adaptabilité ou la plasticité d'espèces potentiellement utiles. Etant donné que l'humidité disponible et la température ont une forte influence sur la survie et la croissance des plantes, ce chapitre se concentre sur ces facteurs.

ACIAR Monograph No. 24. ACIAR, Canberra, Australie.

\section{Problèmes et solutions possibles: choix d'orientations pour le secteur forestier dans la région Asie-Pacifique.}

Byron, N.

Cet ouvrage analyse les principaux problèmes d'orientation auxquels sont confrontés les pays de la région Asie-Pacifique pour réaliser une mise en valeur durable et équitable de leurs forêts, et les possibilités qui s'offrent à cet égard. Il examine les tendances dans le secteur forestier, et les causes économiques, démographiques et sociales qui les déterminent, en particulier la question de savoir qui gérera les forêts dans l'avenir, et pour quels objectifs. Les forces qui interviennent sont notamment les pressions en faveur de la décentralisation, de la corporatisation, de la privatisation et de la délégation à des groupes communautaires locaux, dans le cadre d'un 
mouvement général qui tend à confier à des autorités d'échelon plus local "la barre de la barque, plutôt que les avirons".

L'auteur souligne l'importance sociale et économique actuelle des forêts pour les populations qui vivent à l'intérieur ou à proximité des forêts tropicales dans la région Asie-Pacifique, et suggère des possibilités d'améliorer les conditions économiques, sociales et écologiques des forêts et des populations forestières et riveraines.

Il examine ensuite certaines perspectives de développement dans le secteur forestier, notamment les compromis à long terme possibles entre objectifs et entre besoins économiques, sociaux et écologiques. Il examine enfin les possibilités de négocier des résultats "gagnant-gagnant", et les choix qui s'offrent aux gouvernements des pays de la région AsiePacifique pour des réformes de politiques et d'institutions ainsi que la manière dont ils pourraient être renforcés par des actions internationales.

Asia Pacific Forestry Sector Outlook Study Working Paper Series No. APFSOS/WP/09. FAO Regional Office for Asia and the Pacific (Bureau régional de la FAO pour l'Asie et le Pacifique), Bangkok, Thaïlande. 64p.

\section{Assistance internationale au développement en matière de forêts et d'aménagement des terres: le processus et les acteurs.}

Byron, N.

“Pourquoi tant de projets forestiers d'assistance échouent-ils ?": c'est une question qui est fréquemment posée. La plupart des réponses dressent un bilan des difficultés rencontrées dans leur exécution.

Cet article, au contraire, affirme que la réponse ne peut être trouvée que par la compréhension de deux processus bien plus généraux: la manière dont une activité forestière se relie au contexte socio-économique plus large dans lequel elle se déroule, et la manière dont l'assistance au développement agit en pratique. De nombreux projets que des forestiers considèrent comme des échecs d'un point de vue technique ou même humain peuvent constituer une réussite en fonction d'autres critères politiques ou commerciaux, ou aux yeux d'autres groupes d'intérêt. En dépit des contraintes inhérentes au processus de développement international, de nombreux projets forestiers ont procuré des bénéfices réels et durables pour 
la société, pour l'économie et pour l'environnement. Les projets, surtout ceux ayant un caractère de foresterie sociale, continueront d'échouer si l'on ne prête pas attention, dans leur conception et leur exécution, aux besoins du groupe visé, c'est-à-dire les plus démunis.

Commonwealth Forestry Review 76: 61-8.

\section{Aménagement des forêts feuillus naturelles en Amérique tropicale: bibliographie.}

CATIE et CIFOR.

Afin de contribuer à une meilleure diffusion et une meilleure utilisation de l'information disponible dans la région, le Centre de recherche forestière internationale (CIFOR) et le Centre de recherche et de formation en agriculture tropicale (CATIE) ont décidé d'unir leurs efforts pour entreprendre l'élaboration d'une bibliographie annotée sur les thèmes relatifs à l'aménagement des forêts naturelles en Amérique tropicale. Après plus d'un an et demi d'un travail ardu de divulgation, de compilation, de traitement et de révision, nous avons la satisfaction de présenter cet ouvrage, disponible sous forme imprimée et sur disquette, en tant que premier résultat de l'initiative des deux institutions. La couverture géographique se limite à l'Amérique tropicale, c'est-à-dire depuis le sudest du Mexique jusqu'au nord de l'Argentine, englobant ainsi les forêts néotropicales de zones climatiques tropicales et subtropicales. Néanmoins, l'ouvrage cite aussi des études au niveau pantropical, mais qui font mention des forêts néotropicales. On a inclus des références de livres, d'articles scientifiques et techniques, d'exposés au cours de réunions, d'articles dans des revues non scientifiques, de rapports finals de projets, de bibliographies et de documents audiovisuels. La période couverte est principalement celle qui va de 1950 à mi-1996. Il y a au total 1292 références, relatives en majorité à des documents écrits.

Serie Bibliotecnología y Documentación Bibliográfica No. 26, 1997. CATIE - CIFOR, Turrialba, Costa Rica. 544p. (Comprend une disquette de la base de données). 
Cultivateurs itinérants en Indonésie: maraudeurs ou gestionaires de la forêt : Production de riz et utilisation de la forêt par les Uma' Jalan de Kalimantan Est.

Colfer, C.J. Pierce et Dudley, R.G.

Traduction de Série FAO d'études de cas de foresterie communautaire No. 6 : Les cultivateurs itinérants d'Indonésie: prédateurs ou aménageurs de la forêt ? Production de riz et utilisation de la forêt chez les Uma' Jalan du Kalimantan oriental (1993).

Cette étude examine des données longitudinales sur quatre villages de Dayak Uma' Jalan Kenyah au Kalimantan Timur en relation avec les questions de gestion forestière. La culture itinérante, plutôt que d'être ignorée ou rejetée par les chercheurs et les administrateurs, pourrait servir de modèle pour développer des techniques agroforestières appropriées aux forêts denses tropicales. Les données sont utilisées pour déterminer les tendances dans la surface des défrichements annuels, les préférences en matière de terrains et de forêts, la productivité et les contraintes agrologiques. L'iincidence des facteurs écologiques, sociaux, structurels et technologiques, des catastrophes naturelles et de l'exploitation forestière sur des aspects déterminés des systèmes agroforestiers est également analysée. Les questions de politiques concernent des études de la population, de l'utilisation des terres, de la production et du régime foncier.

Les recommandations présentées en conclusion portent sur une meilleur contrôle de l'exploitation industrielle des bois, la reconnaissance des revendications des populations locales sur leurs terres, l'incorporation de la connaissance autochtone dans les actions de développement, l'arrêt de projets qui entraînent un accroissement de la population du Kalimantan, et une aide financière de la communauté internationale à l'Indonésie pour l'appuyer dans ces efforts.

Samarinda, Indonésie, GTZ, FAO, CIFOR. 158p.

Au delà de la culture sur brûlis: s'appuyer sur la science autochtone pour aménager les forêts denses de Bornéo.

Colfer, C.J. Pierce avec Peluso, N.L. et Chin See Chung.

Cet ouvrage, auquel ont contribué des auteurs divers dont des habitants de la forêt eux-mêmes, décrit le système d'aménagement des ressources 
naturelles pratiqué par les Uma' Jalan Kenyah du Kalimantan Timur en Indonésie. Colfer et ses co-auteurs cherchent à présenter la connaissance qu'ont les populations locales de la forêt qui les entoure et de sa gestion ordonnée d'une manière qui permette à des chercheurs confirmés de la comprendre et de la mettre à profit. La population et sa connaissance de la forêt sont considérées comme partie intégrante de la biodiversité de la forêt.

La destruction et la dégradation rapides des forêts ombrophiles tropicales au cours des dernières années signifient que les seuls moyens d'existence de ces populations qui vivent dans ces forêts et en dépendent sont menacés. La sédentarisation et le mode d'agriculture qui succèdent généralement au défrichement de la forêt ne sont pas de nature à préserver les connaissances et les cultures qui se sont développées au cours des siècles.

Présentant la manière dont les Uma' Jalan perçoivent leurs ressources naturelles, et examinant ensuite leur système agroforestier de ce point de vue, les auteurs analysent la base de subsistance de ces habitants de la forêt. Il définissent le rôle de l'argent dans ce système, et décrivent les choix qui s'offrent à eux pour leur survie. Dans le dernier chapitre ils discutent les répercussions de ces conclusions pour l'aménagement forestier dans les tropiques, en soulignant la manière dont les coutumes des Uma' Jalan pourraient être adaptées pour préserver au moins une partie des forêts en vue de la conservation, de la biodiversité, de la subsistance améliorée de petites populations et de la production soutenue de bois.

New York Botanical Garden Press, New York, 236p.

De l'écorce au bois de cœur: la place des femmes dans l'aménagement forestier. In: Actes de la Conférence internationale sur les femmes dans la région Asie-Pacifique: personnes, pouvoirs et politiques, 11-13 août 1997, RELC, Singapour, 178-95.

Colfer, C.J. Pierce, Wadley, R.L., Woelfel, J. et Harwell, E.

Les études discutées ici avaient pour objet d'évaluer des composantes humaines, précédemment identifiées, de l'aménagement forestier rationnel. Ces composantes humaines sont la sécurité de l'accès aux ressources d'une génération à l'autre, la cogestion des forêts, et la 
définition des partie prenantes légitimes. Diverses méthodes sont actuellement testées du point de vue de leur rentabilité et de leur fiabilité, dans l'espoir de pouvoir évaluer systématiquement le bien-être des populations et leur rôle dans l'aménagement forestier. Parmi les méthodes que nous avons utilisées pour évaluer les composantes humaines de l'aménagement forestier, on peut noter une technique participative de tri de cartes, une cartographie cognitive "Galileo", un formulaire d'histoire locale, une "méthode de continuum itératif", et une cartographie participative. Ces méthodes sont brièvement évaluées vis-à-vis de la connaissance plus qualitative des auteurs de la question des femmes dans le contexte de la recherche, s'appuyant sur une longue expérience de travail ethnographique de terrain. Ce document rapporte nos tentatives et nos difficultés d'intégration de la femme dans le processus d'évaluation.

Département de Géographie de l'Université Nationale de Singapour,

Singapour.

\section{Du bois de coeur à l'écorce en Indonésie: la femme et l'aménagement forestier.}

Colfer, C.J. Pierce, Wadley, R.L., Woelfel, J. et Harwell, E.

Le CIFOR teste depuis 1994 des critères et indicateurs de l'aménagement forestier durable. Les chercheurs de ce projet emploient de nombreuses méthodes pour prendre en compte dans les tests les points de vue des population locales sur leur accès à la forêt. Ils s'intéressent à leur sentiment sur la cogestion des ressources. Les chercheurs évaluent ce qu'ils constatent par les tests au regard de leur propre compréhension qualitative fondée sur un travail ethnographique de longue durée.

Recourant à l'analogie avec un arbre tropical, les auteurs commentent leurs tentatives permanentes d'évaluer la question de la place des femmes dans la mesure où elle a un rapport avec le bien-être humain et avec l'aménagement rationnel des forêts. Ce travail s'appuie sur l'hypothèse que les forêts ne pourront être durablement aménagées que si l'on prête attention aux habitants de ces forêts, tant les femmes que les hommes. Les auteurs concluent qu'il faut encore s'attacher à trouver des méthodes simples, rapides et fiables pour évaluer la sécurité de l'accès des femmes aux ressources d'une génération à l'autre.

Women in Natural Ressources 18(4): 7-14. 


\section{Arbres et arbustes australiens pour la restauration des sols et les plantations fermières dans les tropiques.}

J.C. Doran et Turnbull, J.W. (sous la direction de)

Cet ouvrage est une édition revue et augmentée d'une publication de 1986 intitulée "Multipurpose Australian trees and shrubs: lesser-known species for fuelwood and agroforestry" (Arbres et arbustes australiens à fins multiples: essences peu connues pour la production de bois de feu et l'agroforesterie). Son objet est de servir de texte de référence pour tous les techniciens concernés par le choix et la plantation d'arbres et arbustes dans les zones rurales des pays en développement et dans les régions tropicales de l'Australie. Il présente des descriptions des caractéristiques botaniques, écologiques, sylvicoles et techniques d'essences potentiellement utilisables.

Avec l'amenuisement continu des surfaces de forêts tropicales, et la dégradation de celles qui subsistent, il faut trouver de nouvelles sources de biens et services pour relayer ceux fournis par ces forêts. On assiste à un développement croissant des plantations à petite échelle pour la fourniture de bois et autres produits forestiers. Les petits paysans, notamment en Asie, choisissent de planter des arbres sur leurs terres en petites parcelles, en lignes ou en association agroforestière avec des cultures agricoles.

La recherche d'espèces ligneuses appropriées porte surtout sur l'amélioration de la productivité de celles qui sont déjà utilisées et la découverte de nouvelles espèces répondant à des conditions écologiques et sociales particulières. L'Australie est riche en ressources génétiques de plantes ligneuses, dont beaucoup sont adaptées à des conditions climatiques rigoureuses et à des sols déficients en éléments nutritifs. L'évaluation de ligneux australiens pour répondre aux besoins des populations démunies des pays en développement s'est concentrée sur des espèces ayant une aire de distribution tropicale et subtropicale. Les caractéristiques désirables sont notamment la capacité de fournir des biens et services en plus du bois de feu, l'adaptabilité, la facilité d'installation et d'entretien, et la tolérance à des milieux extrêmes.

ACIAR Monograph No. 24. ACIAR, Canberra, Australie. 
Introduction aux condensés sur les espèces. In: J.C. Doran et Turnbull, J.W. (sous la direction de) Arbres et arbustes Australiens pour la restauration des sols et les plantations fermières dans les tropiques, 89-384.

Doran, J.C., Turnbull, J.W., Martensz, P.N., Thomson, L.A.J. et Hall, $N$.

Ce volume a pour objet de servir de texte de référence pour tous les techniciens concernés par le choix et la plantation d'arbres et arbustes dans les zones rurales des pays en développement et dans les régions tropicales de l'Australie. Cette introduction aux condensés sur les espèces qui suivent décrit les critères utilisés pour choisir les espèces à y inclure.

Les espèces décrites sont celles jugées par un groupe de botanistes et de forestiers expérimentés comme ayant un bon potentiel de production de bois de feu, fourrage, pieux, perches, ombrage et abri, couverture du sol, ou autres produits et influences désirables, ainsi que certaines espèces choisies spécifiquement pour leur intérêt dans l'alimentation humaine. Chacune des 112 espèces principales est illustrée par une photographie en couleurs et une carte de répartition montrant son aire naturelle, et est accompagnée d'une information détaillée sur ses caractères botaniques, sa répartition naturelle, ses exigences écologiques, son utilisation, ses caractéristiques sylvicoles, ses parasites et maladies, ses limitations, et les espèces voisines.

Un tableau général récapitule les espèces décrites et résume leurs principales caractéristiques et utilisations: milieu (climat et sol), comportement, emplois (bois et autres).

ACIAR Monograph No. 24. ACIAR, Canberra, Australie.

\section{Le développement de l'agriculture itinérante et la menace de perte de biodiversité.}

De Jong, W.

L'Indonésie vient au troisième rang mondial pour la superficie de forêts tropicales. Ces forêts ont une très grande valeur du fait de leur grande biodiversité, résultant de la position géographique unique du pays, mais aussi en tant que ressource naturelle économiquement importante. L'exploitation forestière s'est développée en Indonésie avec dans les premières décennies peu de souci de la pérennité des ressources forestières, 
mais depuis peu on observe un changement d'attitude en faveur de véritables politiques de conservation des forêts. Ces politiques, toutefois, concernent principalement le secteur forestier, et beaucoup moins les conflits qui naissent entre l'Etat et les populations tributaires des forêts. Une croyance couramment répandue reste que les cultivateurs itinérants sont responsables de la moitié environ des déboisements annuels en Indonésie. Afin de résoudre ce problème, le gouvernement a défini un certain nombre de mesures pour tenter de convertir les cultivateurs itinérants en agriculteurs sédentaires. L'auteur de cette étude discute ces mesures, et les confronte avec de nouvelles vues sur la nature de la dynamique de l'agriculture itinérante et sur le rôle que la gestion des forêts joue dans cette méthode d'agriculture. Les projets officiels se bornent à proposer des plantations forestières, qui entraînent une perte importante de biodiversité dans le paysage agricole. Prenant un exemple d'agriculture itinérante au Kalimantan occidental, qui comporte un aspect important d'aménagement de la forêt, l'auteur démontre que le développement de régimes existants d'agriculture et d'aménagement de la forêt est suceptible d'apporter un développement économique à la région tout en conservant la biodiversité.

Agriculture, Ecosystems and Environment 62: 187-97.

Exploitation forestière et conservation des forêts dans les tropiques. Actes d'un colloque organisé par le Groupe de travail de I'IUFRO S3.05-00: Exploitation forestière dans les tropiques, au XXème Congrès mondial de I'IUFRO, 6-12 août 1995, Tampere (Finlande).

Dykstra, D.P. (sous la direction de)

Les opérations d'exploitation et de transport des bois sont des éléments essentiels d'une mise en valeur rationnelle des forêts. La reconnaissance de ces facteurs importants s'inscrivait bien dans le thème du XXème Congrès mondial de l'IUFRO, "Prendre soin de la forêt: la recherche forestière dans un monde en mutation". Ce Congrès s'est tenu en août 1995 à Tampere, Finlande. Son programme de travaux comprenait une séance de discussion de nouvelles techniques pour la planification, l'exécution et le contrôle des opérations forestières d'une manière qui favorise un aménagement durable des forêts tropicales. 
Ce volume constitue les actes du colloque organisé par le Groupe de travail de l'IUFRO S3.05-00: "Exploitation forestière dans les tropiques". Un ensemble de techniques y sont discutées dans un certain nombre de régions. Une étude de Migunga discute du tassement du sol forestier en Tanzanie, tandis que Cordero et Howard étudient l'emploi de bœufs pour le débardage au Costa Rica. Rubini Atmawidjaja s'intéresse à la gestion des écosystèmes en Indonésie pour concilier les besoins humains et les exigences écologiques. Elias étudie les dommages d'exploitation forestière au Kalimantan oriental, tandis qu'Aulerich examine l'application de systèmes de débardage par câble-grue par une société indonésienne. Shi Mingzhang présente les travaux d'aménagement forestier réalisés par le Bureau forestier de Leizhou dans la province de Guangdong en Chine méridionale. Une étude de cas au Mexique sur l'évaluation des dommages dans une opération de débusquage est présentée par Hernández-Diáz et Delgado-Pacheco, tandis que Malinovski examine la situation de l'exploitation forestière dans le bassin de l'Amazone. Cedergren et al. évaluent l'effet de coupes sélectives sur les caractéristiques sylvicoles dans une forêt mélangée à diptérocarpacées du Sabah.

IUFRO/CIFOR, Vienne. Egalement disponible en Publication spéciale du CIFOR, 1996, 60p. ISBN 979-8764-10-2

Contexte historique et cadre conceptuel du code modèle d'exploitation forestière de la FAO. In: Etude de techniques d'exploitation forestière écologiquement compatibles avec la conservation des forêts tropicales: Actes de la Réunion satellite FAO/IUFRO tenue conjointement avec le XXème Congrès mondial de I'IUFRO, Tampere, Finlande, 4-5 août 1995, 57-63.

Dykstra, D.P.

Le Code modèle d'exploitation forestière de la FAO, publié début 1995 par l'Organisation des Nations Unies pour l'alimentation et l'agriculture, a pour objet de servir de modèle pour les pays membres de la FAO qui désirent élaborer leur propre code de pratique forestière. Ce document expose les objectifs du Code modèle de la FAO, retrace l'historique des événements qui ont conduit à son élaboration, et résume les fondements doctrinaires sur lesquels il s'appuie. 


\section{Systèmes d'information appliqués à la foresterie.}

Dykstra, D.P.

L'information a toujours constitué un "fonds de commerce" essentiel pour les gestionnaires forestiers. La connaissance des essences forestières, de l'âge des peuplements, des caractéristiques de la croissance, de la qualité de la station, des classes de sol et de relief, des coûts d'exploitation forestière et des débouchés des produits sont depuis des lustres autant d'éléments indispensables pour un aménagement forestier rentable. Ce qui a changé, ce sont les techniques employées pour collecter, analyser et présenter cette information, et en particulier la rapidité de ces opérations. Les gestionnaires forestiers doivent bien appréhender l'incidence de ces nouvelles techniques d'information, et la manière dont les besoins d'information influeront tant sur le personnel que sur la structure de leurs organisations. Cet article considère certaines techniques d'information nouvellement apparues, qui prennent de l'importance pour de nombreuses organisations forestières en tant qu'outils pour améliorer la planification stratégique et tactique et la conduite et le contrôle des opérations.

Unasylva 48 (189): 10-15

Récolte et transport des produits forestiers: problèmes anciens, solutions nouvelles. In: Actes du Xlème Congrès forestier mondial, 13-22 octobre 1997, Antalya, Turquie. Vol. 3, D: Fonctions de production des forêts.

Dykstra, D.P. et Heinrich, R.

Les opérations d'exploitation forestière et de transport des produits se déroulent dans des conditions presque idéales pour créer des conflits. C'est pourquoi il importe de les mener avec le plus grand soin non seulement pour assurer la bonne conservation des forêts mais également pour préserver la profession forestière elle-même. Cet exposé résume des initiatives récentes visant à réduire les impacts écologiques et sociaux associés à l'exploitation forestière et au transport des produits. Elles comprennent des efforts en vue de réduire l'étendue mondiale des coupes forestières en forêts naturelles en accroissant le rendement de celles-ci; la recherche d'une meilleure rentabilité économique grâce à une meilleure planification et un meilleur contrôle des opérations et une meilleure formation de la main-d'œuvre forestière; des initiatives pour développer des systèmes d'incitation et des politiques 
encourageant l'adoption de méthodes d'abattage et de débardage à faible impact; des efforts pour définir des directives locales et régionales en vue de pratiques respectant le milieu forestier; des travaux d'élaboration de procédures d'évaluation de la gestion forestière durable. Les auteurs passent d'autre part brièvement en revue un choix de progrès techniques récents susceptibles de rendre les opérations d'exploitation et de transport à la fois plus rentables économiquement et moins dommageables pour l'environnement.

Comité d'organisation du Congrès forestier mondial, Ankara, Turquie.

\section{Promotion de l'aménagement forestier dans la zone de forêt tropicale humide d'Afrique occidentale et centrale anglophone. 133p. \\ Dykstra, D.P., Kowero, G.S., Ofusu-Asiedu, A. et Kio, P.}

Ce projet financé par le PNUE et mis en oeuvre par le CIFOR s'est intéressé aux forêts tropicales humides d'Afrique occidentale, plus particulièrement au Ghana et au Nigeria, avec des informations complémentaires provenant du Libéria, de Sierra Leone et du Cameroun. L'objectif général était de faire une synthèse de toute l'information disponible sur les formations forestières humides d'Afrique occidentale afin de catalyser les initiatives susceptibles de favoriser l'adoption de principaes de gestion durable des forêts dans toute la région.

Le rapport se divise en neuf chapitres. Le premier chapitre décrit la situation des forêts en Afrique occidentale et centrale, en s'intéressant notamment à la distribution de la végétation et aux facteurs qui influent sur la distribution des forêts. Les chapitres 2 et 3 décrivent les techniques de sylviculture et d'aménagement forestier passées et actuelles, ainsi que les systèmes de contrôle de l'aménagement. Les aspects relatifs à la biodiversité, et le rôle des produits forestiers autres que le bois, sont examinés au chapitre 4. Les relations entre générations, les facteurs socioéconomiques qui influent sur la gestion des forêts, et les questions de politique et de législation, sont traités dans les chapitres 5, 6 et 7. Le chapitre 8 esquisse les stratégies et les incitations qui pourraient être adoptées pour promouvoir un aménagement durable des forêts. Le rapport conclut par des suggestions de recherches pouvant être entreprises pour 
combler les lacunes dans les connaissances qui sont apparues au cours de ce projet.

Grâce à des fonds publics français, le CIFOR et le CIRAD mènent un projet analogue sur les forêts tropicales humides de Côte d'Ivoire, du Cameroun, de République Centrafricaine, de la République Populaire du Congo et du Gabon.

ISBN 979-8764-09-9 (Anglais) ISBN 979-8764-14-5 (Français)

Réponse des peuplements forestiers tropicaux aux interventions sylvicoles. In: Actes du Xlème Congrès forestier mondial, Antalya, Turquie, 13-22 octobre 1997. Vol. 3, 118-22.

Favrichon, V., Dupuy, B., Maitre, H.F., Nguyen-The, N., Damio, T., Doumbia, N., Kadir, K., Petrucci, Y. et Sist, P.

Le Programme de recherche du CIRAD-Forêt sur la dynamique des forêts tropicales humides se poursuit depuis 1974 en collaboration avec divers instituts nationaux de recherche forestière. La recherche est menée sur un réseau de parcelles expérimentales, dont les plus importantes sont situées en Afrique (Mopri, Irobo et La Téné en Côte d'Ivoire et M'baiki en République Centrafricaine), en Amérique du Sud (ZF2 à Manaus au Brésil et Paracou en Guyane Française), et en Asie (Strek à Berau en Indonésie). Ces parcelles ont été conçues avec une méthodologie commune, et font l'objet d'un suivi régulier. Elles permettent d'étudier la dynamique des écosystèmes de forêt tropicale humide et la réponse de différents types de forêt aux perturbations telles qu'exploitation forestière et éclaircies sanitaires. De nombreuses recherches y ont été menées. Certains des résultats obtenus ont déjà conduit à la réalisation de projets d'aménagement forestier à grande échelle fondés sur le principe du rendement soutenu (à Yapo en Côte d'Ivoire, par exemple). L'objet de cet article est de présenter une vue générale de ces parcelles et d'exposer dans les grandes lignes les principales tendances de la réponse des peuplements forestiers aux interventions sylvicoles. La première partie présente les paramètres de la forêt naturelle moyenne (en ce qui concerne la rapidité de croissance, l'expansion et la mortalité). En montrant comment ces paramètres changent dans le temps après des interventions sylvicoles, on peut évaluer l'effet de la densité du peuplement sur sa productivité et 
l'influence des coupes et des éclaircies sur la rapidité de reconstitution du peuplement forestier.

Comité d'organisation du Congrès forestier mondial, Ankara, Turquie

Cartographie de la distribution potentielle des espèces végétales et animales en vue de l'aménagement de la faune sauvage: emploi du programme informatique DOMAIN. In: Romimoharto, K., Hartono, S. et Sonarno, S.M. (sous la direction de), Actes du séminaire national sur le rôle de la conservation de la faune sauvage et de son écosystème dans le développement national, 114-19 + deux cartes.

Gillison, A.N.

Une connaissance suffisante de la distribution des espèces et de leur comportement est fondamentale pour un aménagement rationnel de la faune sauvage. Dans la majorité des cas où l'on n'a qu'une connaissance très limitée de cette distribution, il peut être nécessaire d'avoir d'autres moyens d'acquérir l'information afin de pouvoir modéliser la distribution potentielle des espèces faisant l'objet de l'aménagement. Ce document passe brièvement en revue certains programmes informatiques actuellement disponibles, notamment la version pour Windows de DOMAIN mise au point au CIFOR. A la différence de certains autres programmes cartographiques, le programme DOMAIN peut fonctionner efficacement avec un nombre relativement faible de points de distribution connus. Ceux-ci sont mis en corrélation avec les valeurs d'autres variables écologiques spatialement référencées telles qu'altitude, sols, type de végétation, climat, considérées comme influant sur la distribution des espèces.

Une enveloppe d'habitat ou domaine écologique est alors établi par ordinateur à partir de ces corrélations. L'algorithme fait ensuite correspondre le gabarit avec les valeurs connues des variables écologiques pour tous les pixels de la surface étudiée, et cartographie des classes de similitude. On peut ainsi faire une estimation rapide de la distribution potentielle d'une ou plusieurs espèces pour toute zone où l'on dispose de données écologiques appropriées spatialement référencées. Une étude de cas dans le centre de Sumatra démontre comment cette méthode peut être utilisée pour établir des cartes de diversité ou de richesse des espèces végétales.

Fonds Indonésien pour la nature (IWF), Djakarta, Indonésie 
Emploi d'un jeu d'attributs fonctionnels des plantes et d'une syntaxe pour la description et l'analyse dynamiques de la végétation.

Gillison, A.N. et Carpenter, G.

Les méthodes classiques de description de la végétation renseignent rarement sur le comportement ou la réponse de la végétation, qu'il serait nécessaire de connaître pour décrire la végétation mondiale d'une manière qui réponde aux besoins de la conservation et de l'aménagement. On peut déduire l'information nécessaire à cet effet à l'aide d'un jeu d'attributs fonctionnels des plantes (AFP) tel que décrit dans ce document.

Une syntaxe fournit un ensemble de règles pour créer et comparer des modèles fonctionnels fondés sur des combinaisons spécifiques d'AFP. Cette méthode facilite une estimation rapide et uniforme de la réponse des plantes aux variations du milieu physique à différentes échelles de temps, indépendamment de l'espèce. Son application est illustrée par des études de cas locales, régionales et mondiales.

Functional Ecology 11: 775-83.

\begin{abstract}
Alimentation azotée à partir du sol et des insectes au cours de la croissance des plantes insectivores Nepenthes mirabilis, Cephalotus follicaris et Darlingtonia californica.
\end{abstract}

Gillison, A.N., Schulze, W., Schulze, E.D. et Pate, J.S.

Les auteurs ont étudié l'alimentation en azote à partir du sol et de la capture d'insectes durant la croissance de trois espèces de plantes insectivores, Nepenthes mirabilis, Cephalotus follicaris et Darlingtonia californica. On a utilisé les taux d'abondance naturelle d'isotope $\mathrm{N}^{15}$ (rapport $\mathrm{d}^{15} / \mathrm{N}^{14}$ ou $\mathrm{dN}^{15}$ ) de plants et d'urnes de différents âges, de plantes de référence non carnivores et d'insectes proies pour estimer la contribution relative des insectes à la teneur en $\mathrm{N}$ des feuilles et des plantes entières. De jeunes feuilles de Nepenthès (phyllodes) portant des urnes fermées constituent des réservoirs $\mathrm{d}$ 'N, et elles se développent principalement à partir de l'azote d'insectes capturés dans d'autres parties de la plante. Leur indice $\mathrm{dN}^{15}$, pouvant atteindre 7,2\%, est supérieur à la valeur moyenne de $\mathrm{dN}^{15}$ d'insectes capturés (valeur moyenne de $\mathrm{dN}^{15}=5,3 \%$ ). Dans des feuilles portant des urnes âgées agissant comme 
sources d'N, l'indice $\mathrm{dN}^{15}$ descend à $3,0 \mathrm{o} / \mathrm{oo}$, ce qui indique soit une contribution accrue de l'N du sol à ces parties de la plante qui en fait ont capturé les insectes, soit un gain d'N provenant de la fixation d'azote atmosphérique par des microorganismes présents dans les urnes âgées. L'indice dN15 de l'azote dans de l'eau prélevée dans des urnes âgées est de 1,2 o/oo, et cette eau contient des acides aminés libres. La fraction d'N provenant d'insectes dans des urnes jeunes et âgées et dans les feuilles associées descend de 1,0 à $0,3 \mathrm{mg} / \mathrm{g}$. Cette fraction décroît encore avec la taille du plant étudié. Les népenthès contiennent en moyenne 61,5 \pm 7,6 \% (moyenne \pm écart-type, amplitude 50-71\%) d'N provenant d'insectes par rapport à la teneur totale en $\mathrm{N}$ de la plante. En l'absence de plantes de référence non carnivores appropriées pour Cephalotus, on a évalué les valeurs de $\mathrm{dN}^{15}$ sur une séquence de développement de jeunes plants dépourvus d'urnes à des adultes en possédant jusqu'à 38. Les données recueillies indiquent que la plante est tributaire de l' $\mathrm{N}$ du sol jusqu'à ce qu'elle ait 4 urnes ouvertes. Au delà de ce stade la taille de la plante s'accroît en même temps que le nombre d'urnes pièges, mais la fraction d'N provenant du sol reste élevée. On a estimé que de grands plants de Cephalotus tirent $26 \pm 5,9 \%$ (moyenne \pm écart-type, amplitude 19-30\%) d'N provenant d'insectes. On a observé chez Cephalotus une valeur accrue de $\mathrm{dN} 15$ dans des urnes de stockage par rapport aux urnes de capture, d'environ 1,2 o/oo en moyenne. Des urnes de capture et de stockage de Darlingtonia avaient des valeurs de aN15 comparables, mais l'N de la plante dans cette espèce montrait des indices $\mathrm{dN} 15$ plus proches de l'N provenant d'insectes représentait 76,4 $\pm 8,4 \%$ (amplitude 57-90\%) de la teneur totale en $\mathrm{N}$ de l'urne. Les résultats semblent indiquer qu'il existe des modes complexes de répartition de l'N provenant d'insectes et du sol entre les régions d'absorption et de stockage d'N chez ces plantes insectivores, et sans doute une plus forte dépendance vis-à-vis de l'N provenant d'insectes qu'il n'a été observé ailleurs sur Drosera spp.

Oecologia 112: 464-71 
Mesures possibles pour renforcer la juridiction internationale concernant les forêts. Rapport établi pour la Commission Européenne au titre du contrat d'étude B7-8110/96/000221/D4. Gluck, P., Tarasofsky, R., Byron, N. et Tikkanen, I.

Des propositions de Convention mondiale légalement contraignante sur les forêts, discutées et rejetées au Sommet mondial CNUED de 1992 à Rio de Janeiro, resurgissent périodiquement à l'occasion de réunions internationales. L'argument en faveur d'une action mondiale concertée repose sur l'existence de "problèmes internationaux" pour lesquels ce serait le seul remède, alors que des conventions sont inutiles et inadaptées pour les problèmes nationaux. Les valeurs mondiales des forêts sont leur diversité biologique et leur rôle de stockage du carbone. Il y a d'autre part une préoccupation internationale croissante au sujet du défrichement et de la dégradation des forêts, compromettant la vie et la culture des populations forestières, et de la perte des connaissances traditionnelles sur la flore et la faune. Ce rapport soutient que bon nombre des préoccupations exprimées au sujet des forêts ont une origine et des conséquences locales ou nationales. Les politiques nationales et sectorielles ont encouragé la conversion de forêts à d'autres utilisations, et certaines politiques forestières ont encouragé la surexploitation. Le statut foncier des terres forestières reste souvent peu clair, ou est contesté, et les forêts ont fréquemment été soumises à une exploitation minière pour un profit rapide, et ensuite abandonnées ou livrées aux colons agricoles ou aux planteurs industriels.

La plupart des aspects "mondiaux" des questions forestières sont déjà pris en compte dans d'autres conventions de la CNUED. Il serait sans doute plus facile et plus rationnel d'améliorer l'efficacité des accords existants et de la collaboration volontaire. Les instruments juridiques, politiques et économiques existants permettent de traiter les problèmes. Le rapport examine la faisabilité, la probabilité et le coût d'un accord créant un nouvel instrument, et ensuite de l'application de cet instrument, ainsi que les effets probables sur la distribution, tant entre pays qu'à l'intérieur des pays.

Même si elle n'est pas indispensable, une convention pourrait regrouper les législations internationales fragmentaires portant sur les forêts, et offrir un lieu de discussion pour l'analyse et la convergence 
d'opinions. Ou bien elle pourrait n'être qu'une excuse pour se dispenser d'actions plus efficaces.

Institut Forestier Européen, Joensuu, Finlande. 78p.

\section{Anthropologie du climat dans le monde Hispano-Américain. Goloubinoff, M., Katz, E. et Lammel, A. (sous la direction de)}

La relation entre l'homme et le climat est une longue histoire. Cependant elle n'a été que peu étudiée du point de vue des sciences humaines. En général, les facteurs climatiques et les relations homme-climat font l'objet d'une brève description dans les études ethnographiques, mais peu de travaux ont été consacrés à ce thème. L'objet de la présente étude est de développer comme champ de recherche l'anthropologie du climat, que nous définirons comme l'étude de l'interaction entre les facteurs climatiques et les cultures humaines. Il ne s'agit pas uniquement de l'action des facteurs climatiques sur les êtres humains, mais plutôt d'une interaction dans les deux sens, étant donné que l'influence des activités humaines sur le climat ne fait plus aucun doute du point de vue des sciences exactes. En effet, c'est l'aspect anthropologique qui prédomine dans cet ouvrage. L'anthropologie ne peut toutefois aborder ce thème sans le concours d'autres disciplines; c'est pourquoi y ont contribué des géographes, des historiens, des archéologues, des sociologues, des architectes, des biologistes, des hydrologues et des météorologues. Cet ouvrage traite de la relation homme-climat en Amérique Latine et en Espagne. Il commence par des chapitres d'ordre général qui posent des questions théoriques et méthodologiques à propos de l'anthropologie du climat, et se poursuit par des études de cas dans des sociétés passées et actuelles.

Quito, Abya-Yala. Colección Biblioteca Abya-Yala No. 49. Tomo 2. $315 p$. \& $292 p$. 
Mesure et prise en compte des valeurs de la forêt pour la prise de décisions. In: Actes du Xlème Congrès forestier mondial, 13-22 octobre 1997, Antalya, Turquie. Vol. 4: La contribution économique de la forêt au développement durable, 197-207. Gregersen, H., Lundgren, A., Kengen, S. et Byron, N.

Les forêts procurent d'importants avantages. Les décisions concernant la production de ces avantages sont généralement prises localement, ou au plus au niveau national (par les gouvernements). Pourtant, nombre de ces avantages ont un caractère mondial, et se situent en dehors du contexte des décisions locales ou nationales. Ils sont ce que les économistes appellent des "externalités" pour la prise de décisions. Les auteurs discutent les questions relatives à la prise en compte de ces valeurs de la forêt, ou à "l'internalisation des externalités". Dans un contexte politique, la question se pose de l"appropriation", à savoir qui paie et qui gagne: quels mécanismes peut-on développer pour que les preneurs de décisions prennent en compte la valeur des externalités positives et soient contraints de payer pour les externalités négatives qu'ils créent ? Si cela n'est pas le cas, il est peu probable qu'ils les prendront en considération dans leurs décisions. La manière dont les diverses valeurs de la forêt peuvent être estimées et chiffrées est ensuite brièvement examinée. La dernière partie du document discute de la question de la présentation de l'information sur les valeurs de la forêt aux autorités responsables, en insistant plus particulièrement sur les questions relatives à l'élaboration d'un système de comptabilité écologique utile et efficace pour les forêts.

Comité d'organisation du Congrès forestier mondial, Antalya, Turquie.

Régénération forestière sur les pistes de débardage abandonnées dans les forêts de plaine du Costa Rica.

Guariguata, M.R. et Dupuy, J.M.

Cette étude a inventorié les régénérations sur quatre anciennes pistes de débardage (700-1 $000 \mathrm{~m}$ de longueur) dans des forêts de plaine du Costa Rica exploitées sélectivement, 12-17 ans après leur abandon. Des placettes de $4 \mathrm{~m}^{2}$ furent mises en place à intervalle de $20 \mathrm{~m}$ dans trois microhabitats distincts: chaussée (sol superficiel éliminé), bordures de piste (où le sol superficiel enlevé s'accumule sur les côtés après ouverture de la piste), et 
forêt exploitée contiguë. La densité de tiges de plus de $1 \mathrm{~m}$ de hauteur et d'au moins $5 \mathrm{~cm}$ de diamètree à hauteur d'homme (arbres de l'étage dominant et de l'étage intermédiaire, lianes, palmiers, arbustes, fougères arborescentes) est plus forte sur les placettes de bordure de piste que sur celles situées sur la chaussée ou dans le peuplement exploité. Cet "effet de bordure" est vraisemblablement dû à la germination de graines enterrées d'essences arborescentes et arbustives de lumière après une perturbation modérée du sol, avec un tassement moindre et une meilleure fertilité du substrat que sur les chaussées. La richesse spécifique est la moins élevée, mais la dominance relative la plus forte, sur les placettes sur chaussée de toutes les pistes: 6-9 constituent à elles seules 50\% de l'indice d'importance, tandis qu'il en faut 11-15 et 16-22, respectivement, pour atteindre un indice de 50\% sur les placettes de bordure et les placettes en forêt. Il apparaissait un tassement du sol sur les chaussées de trois des quatre pistes, ce qui, en outre de la faible fertilité initiale du substrat et du manque initial de propagules sur place, pourrait expliquer le rétablissement plus lent de la densité de tiges et de la richesse spécifique en comparaison des placettes de bordure et en forêt. Pour les tiges de 5 à $20 \mathrm{~cm}$ de diamètre à hauteur d'homme, la densité et la surface terrière sur les placettes sur chaussée étaient en moyenne d'environ un quart de celles des placettes de bordure et en forêt. Nous avons estimé que le rétablissement de la surface terrière sur les chaussées prendrait au moins 80 ans pour retrouver la valeur constatée en forêt exploitée, et que celui de la richesse spécifique prendrait encore plus longtemps. Nous suggérons que les pistes de débardage abandonnées servent de couloirs de caractéristiques floristiques et structurelles relativement uniformes et durables, qui pourraient conférer aux forêts exploitées sélectivement des rôles écologiques particuliers.

Biotropica 29: 15-28. 


\section{Structure et composition floristique des forêts secondaires et} des vieilles forêts de plaine du Costa Rica.

Guariguata, M.R., Chazdon, R.L., Denslow, J.S., Dupuy, J.M. et Anderson, $L$.

Cette étude porte sur la structure des peuplements et la composition floristique de la végétation ligneuse dans trois peuplements secondaires âgés de 16-18 ans provenant de régénération après abandon de pâturages, et trois peuplements âgés de forêt dense tropicale de plaine au Costa Rica. La surface terrière et la densité de tiges pour quatre classes de dimension (semis, gaulis, perchis, arbres adultes) étaient comparables dans les deux types de peuplements, mais la densité de palmiers adultes dominants (sujets de plus de $10 \mathrm{~cm}$ de diamètre) était plus faible dans les peuplements secondaires. Le recrû ligneux rapide observé, en comparaison d'autres études publiées dans les zones de plaine néotropicales, peut être attribué à une mise en valeur agricole modérée et sans doute à l'influence de sols volcaniques riches en éléments nutritifs dans la zone d'étude. Dans l'ensemble, la richesse spécifique est moindre dans les peuplements secondaires, mais la différence est moins prononcée dans les plus petites classes de dimension (semis, gaulis). La similitude des pourcentages médians dans toutes les comparaisons par paires de peuplements montre que la composition floristique des gaulis (tiges de plus de $1 \mathrm{~m}$ de hauteur et $5 \mathrm{~cm}$ de diamètre) est plus comparable entre peuplements secondaires et vieille forêt que pour les arbres adultes (tiges de plus de $10 \mathrm{~cm}$ de diamètre). Etant donné que la valeur potentielle des forêts secondaires pour la conservation de la diversité des végétaux ligneux s'avère supérieure pour les jeunes classes de dimension, nous suggérons que des études plus poussées sur la composition floristique, en ce qui concerne notamment la dynamique du sous-étage, seront nécessaires pour affiner notre compréhension du rôle de cette ressource naturelle dans le maintien de la biodiversité végétale dans des paysages perturbés. 
Détection de la variation d'isozyme chez quatre espèces d'arbres fruitiers (Garcinia mangostana, Parkia javanica, Nephelium lappaceum, dan Artocarpus heterophyllus) en utilisant les techniques d'électropohorèse a base de gel d'amidon. In: Moeljopawiro, S., Herman, M., Saono, S., Mariska, I., Purwantara, B. \& Kasim, H. Actes du Colloque de l'Association indonésienne de biotechnologie agricole, Surabaya (Indonésie), 12-14 mars 1997, 158-73.

Hartati, N.S., Sudarmonowati, E.. Fahdiar, A. \& Siregar, U.J.

Les méthodes d'électrophorèse d'isozymes faisant appel à un gel d'amidon sont bien au point pour la détection et l'analyse de la variation génétique dans les plantes. Dans cette étude, on a optimisé les techniques d'électrophorès afin d'obtenir une bonne résolution des diagrammes de bandes, essentielle pour l'analyse des isozymes. On a recouru à des modifications des fauteurs suivants: composition des solutions tampon d'extraction et des systèmes de tampons électrophorétiques, procédures de coloration d'enzymes, extraction d'enzymes de différents tissus de la plante. Onze systèmes d'enzymes ont fait l'objet d'essais à partir d'extraits de feuilles, d'embryons ou d'hypocotyles des espèces suivantes: manggis ou mangoustan (Garcinia mangowana), petai (Parkia javanica), ramboutan (Nephelium lappaccum) et nangka ou jaquier (Artocarpus heterophyllus), en utilisant trois formules de solution tampon d'extraction. Cinq systèmes de tampon électrophorétique ont été expérimentés: Lithium, Histidine $\mathrm{pH}$ 8.0, Histidine $\mathrm{pH}$ 6.0, Citrate de morpholine, Borate de sodium. Ces expériences ont permis d'ifentifier aisément les systémes d'enzymes; suivants; Aspartate amino transférase (AAT), Acide phosphatase (ACP), Peroxydase (PER), Malate dehydrogénase (MDH), Isocitrate déhydrogénase (MDII), Isocitrate déhydrogénase (IDH), Shikimate déhydrogénase (SDH), 6-phosphogluconate déhydrogénase (6-PGD). Sur 11 systèmes d'enzymes, 8 ont été détectés dans le mangouitan, 9 dans le jaquier, 9 dans le petai, et 8 dans le ramboutan. La plupart des systèmes détectés l'ont été à partir d'extraits de feuilles, qui ont également donné la meilleure résolution des diagrammes de bandes. Le système tampon d'électrophorése le plus approprié pour ces, 4 espèces est le Citrate de morpholine $(\mathrm{MC})$. Ces expériences ont d'autre part décelé une grande variation génétique dans ces espèces qui sont importantes pour do futures études do diversité génétique.

Perhimpunan Bioteknologi Pertanian Indonesia. 
Un siècle de culture de caféiers. Dynamique des agroécosystèmes de caféières dans la région des Mixtèques, Mexique. In: Katz, E., Simposio "Los Campesinos del Café en el Pasado y Presente de América Latina" (Colloque sur "Les paysans cultivateurs de café d'Amérique Latine dans le passé et le présent"), Congreso Internacional de los Americanistas (Congrès international d'américanistes), Quito, 7-11 juillet 1997.

Katz, E.

- Résumé non disponible -

Les produits forestiers autres que le bois dans la région de Bulungan, Kalimantan Oriental, Indonésie. In: Mittelman, A.J., Lai, C.K., Byron, R.N., Michon, G. et Katz, E. Etude de perspective sur les produits forestiers autres que le bois à l'horizon 2010 dans la région Asie-Pacifique. 39-46.

Katz, E.

Ce sous-chapitre examine les tendances en matière de produits forestiers autres que le bois dans la zone désignée comme Forêt de recherche de Bulungan, qui a été affectée par le gouvernement indonésien au CIFOR dans un but de recherche. La forêt de recherche couvre 303000 hectares dans le district de Bulungan, Kalimantan oriental, entre les rivières Malinau et Bahau, jouxtant le Parc national de Kayan-Mentarang. Les produits considérés comprennent des mammifères et des oiseaux, le camphre, le gaharu, la gutta-percha, les noix d'illipé, la résine de dammar et le rotin. Cet article soulève d'autre part des questions sur la manière dont ces tendances et ces scénarios se dérouleront dans l'avenir dans des zones telles que Bulungan.

Asia-Pacific Forestry Sector Outlook Study Working Paper, APFSOS/WP/28. FAO, Division de la politique et de la planification forestières, Rome et Bureau régional de la FAO pour l'Asie et le Pacifique, Bangkok. 
Conférence régionale pour l'Afrique sur la conservation, l'aménagement et l'utilisation des plantes fournissant des gommes, des résines et des huiles essentielles, Nairobi (Kenya), 6-10 octobre 1997. Journal d'agriculture traditionnelle et de Botanique appliquée, 39(1): 179-81.

Katz, E.

- Résumé non disponible -

Rites, représentations et météorologie dans la Terre de la pluie, (Mixteca, Mexique). In: Goloubinoff, M., Katz, E. et Lammel, A. (sous la direction de).

Katz, E.

Il est difficile d'imaginer que le climat ne soit pas important pour les Mixtèques, étant donné qu'ils s'appellent eux-mêmes "le peuple de la pluie". L'élément qui caractérise le plus le climat de leur région est l'alternance entre la saison des pluies et la saison sèche. La principale culture vivrière, le maïs, est tributaire des précipitations, peu de zones étant irrigables. L'attente des premières pluies est source d'anxiété. L'excès de pluie, à son tour, peut être dommageable. Pour contrôler cet élément si aléatoire, les Mixtèques pratiquent des rites pour demander ou empêcher la pluie, et ont développé diverses méthodes de prévision climatique. La pluie et la sécheresse servent d'axe symbolique dans les pratiques quotidiennes telles que l'agriculture et la cuisine, et dans l'expression de la reproduction, des processus de la vie, de la fertilité et de l'abondance. En même temps, le cycle de la pluie est représenté comme le cycle de la vie humaine. Tous les phénomènes météorologiques sont reliés à la pluie, mais certains peuvent aussi être "secs" ou "de pluie", comme le vent, les tornades, la foudre. Le passage de la pluie à la sécheresse (et viceversa), marqué par des rites, est comparé au passage de la vie à la mort, de ce monde à l'autre monde.

Antropología del clima en el mundo hispanoamericano (Anthropologie du climat dans le monde hispano-américain), Quito, Abya-Yala. Tome 2. 99-134. 
Les stratégies territoriales face à l'Etat: un exemple d'appropriation de l'espace au Kouilou, Congo. In: Bonnemaison, J., Cambrézy, L. et Quinty-Bourgeois, L. (sous la direction de) Le territoire, lien ou frontière ? Identités, conflits ethniques, enjeux et recompositions sociales (Colloque ORSTOM-Paris IV, Paris, 2-4 octobre 1995), Paris.

Katz, E. et Nguinguiri, J.C.

Sous le régime "marxiste scientifique", les identités ethniques et claniques ont été gommées. Mais, comme dans tout l'ancien bloc socialiste, elles resurgissent de plus belle malgré l'important brassage de population qui a eu lieu dans les villes et le long de la ligne de chemin de fer 16. Mais comme pour les récents conflits politiques à Brazzaville (Dorier-Apprill, 1995), la coloration ethnique des revendications au Kouilou est toutefois à nuancer. Nous avons vu que des membres de la même ethnie peuvent s'affronter, entre autochtones et migrants, pour l'appropriation des ressources naturelles. L'ethnie ou le clan fonctionne en tant que groupe stratégique, au même titre que le réseau de solidarité villageois ou les associations. Le groupe se définit en fonction d'intérêts locaux et ponctuels au travers de relations de clintélisme. Si les ressources halieutiques diminuent dans un village habité à la fois par des Vili et des Téké, c'est autour de l'ethnie que se fédèrent les conflits. Si les dissensions s'opèrent autour des plantations d'eucalyptus, les villages s'appuient sur l'association ou bien jouent la carte de la tenure foncière clanique. La référence à la tradition sert de prétexte et varie aussi selon le contexte: ici, croyance au génie, là, appropriation coutumière des terres.

Mais prétexte ou non, la tradition est toujours vivante et s'adapte au changement. Pour les populations du Kouilou, comme pour d'autres sociétés (Bonnemaison, 1992; Vincent, 1995), le territoire qu'elles occupent est chargé d'histoire et de géo-symboles, tant sur le plan visible qu'invisible, et son appropriation est le fait des génies tutélaires. Les marques matérielles de l'histoire y étant rares, la géographie symbolique prend encore plus d'importance qu'ailleurs. Ceux qui viennent de l'extérieur pour exploiter des ressources peuvent le faire tant qu'ils s'acquittent correctement de leurs redevances face aux gérants visibles et invisibles du territoire; mais de toutes façons, leur passage en ces lieux est éphémère car la permanence est aux génies. 
Facteurs déterminant un faible taux de déboisement: enseignements tirés de l'Amazonie bolivienne.

Kaimowitz, $D$.

L'auteur analyse les facteurs qui déterminent un faible taux de déboisement en Bolivie, en s'appuyant sur l'expérience bolivienne et sur la littérature générale concernant le déboisement, et sur les enseignements tirés dans d'autres pays ayant un faible taux de déboisement. Une faible demande intérieure de produits agricoles et une infrastructure de transport médiocre sont les principales causes du faible taux de déboisement. La faible demande intérieure est liée à une population peu nombreuse et à un faible revenu par habitant, et la déficience d'infrastructure de transport est fonction de la faible capacité d'investissement du pays dans ce domaine, et de facteurs politiques. La production en vue de l'exportation joue un rôle important dans le déboisement dans de tels contextes, et elle est influencée par des politiques telles que construction de routes, hausse des taux de change et subventions pour l'agriculture de rente. Les facteurs influant sur le défrichement par les familles pauvres sont moins nets. Les facteurs politiques et institutionnels méritent plus d'attention que ce n'a été le cas jusqu'à présent dans la littérature sur le déboisement.

Ambio 26: 537-40.

Les progrès de l'agriculture permanente en Amérique Latine. In: Almeida, J. et Navarro, Z. (sous la direction de). Reconstruire l'agriculture: idées et idéaux dans une perspective de développement rural durable, 56-71. Editora da Universidade, Universidade Federal do Rio Grande do Sul, Porto Alegre, Brésil. Kaimowitz, $D$.

Ce document fait le point des progrès de l'Amérique Latine dans la recherche d'une agriculture plus permanente, et de certains facteurs qui expliquent le degré actuel d'avancement. Il cherche à dresser un bilan mondial du chemin parcouru dans cette voie, des obstacles rencontrés et des objectifs que l'on peut raisonnablement espérer atteindre. On entend par agriculture permanente ou durable une agriculture qui permette de nourrir et vetir toute la population à un coût raisonnable, qui offre à ceux qui en dépendent un niveau de vie acceptable, et qui dégrade peu la base de ressources naturelles. L'auteur conclut que, à l'échelle mondiale, les progrès en direction d'une agriculture 
plus stable sont peu marqués. Cependant, ce panorama général masque le fait que des progrès importants ont été réalisés dans certains domaines ou en certains endroits. Le document est divisé en six sections. La première analyse les changements généraux concernant la sécurité alimentaire et les revenus des populations rurales. La deuxième examine les tendances générales concernant la dégradation des ressources naturelles en rapport avec l'agriculture. La troisième, la quatrième et la cinquième sections analysent les progrès de l'agriculture stable en ce qui concerne les politiques des institutions et la technologie, et la sixième présente quelques conclusions finales.

Modes d'utilisation des terres et gestion des ressources naturelles en Amérique Centrale. In: Neidecker-Gonzáles, O. et Scherr, S. (sous la direction de) Développement agricole, stabilité et lutte contre la pauvreté en Amérique Latine: le rôle des régions de versants. Actes de colloque, Tegucigalpa (Honduras), 4-8 décembre 1995, 105-124.

Kaimowitz, $D$.

Cet essai analyse certaines tendances dans les modes d'utilisation des terres dans les zones de versants d'Amérique Centrale au cours des quinze dernières années, pour savoir comment elles se sont produites et quel a été leur impact sur les ressources naturelles. Il commence par une discussion sur les notions d'intensification et d'extensification et leur relation avec la gestion des ressources naturelles. L'auteur décrit trois cas empiriques d'intensification - le développement de l'horticulture sur les hauts plateaux du Guatemala, l'expansion du caféier au Honduras, et l'adoption de la conservation des sols au Nicaragua - suivis de deux cas d'extensification - l'abandon de pâturages au Costa Rica et l'extensification de l'utilisation des terres dans le nord et l'est du Salvador. Enfin, à partir de ces cas, il tire des conclusions générales sur la formulation de politiques appropriées pour la gestion des ressources naturelles dans les zones de versants. 
Politiques influant sur la déboisement en vue de l'élevage en Amérique Centrale. In: de Groot, J.P. et Ruben, R. (sous la direction de) Agriculture stable en Amérique Centrale, 56-71.

Kaimowitz, D.

Le changement le plus important dans l'utilisation des terres en Amérique Centrale dans les 40 dernières années est la conversion à grande échelle de forêts en pâturages. La littérature présente un certain nombre d'explications à cette expansion. Selon les facteurs qui sont considérés comme importants, les pronostics et les recommandations de politiques pour répondre à ces problèmes différeront. Cette étude part de l'expérience d'Amérique Centrale pour avancer certaines hypothèses au sujet des facteurs qui influent sur la conversion des forêts en pâturages, et de l'efficacité réelle ou probable de politiques visant à résoudre les problèmes nés de cette conversion.

Les conclusions tirées de cette étude indiquent que les prix du marché de la viande de bœuf et des produits laitiers, les changements technologiques et les politiques de contrainte sur les prix des bois n'ont qu'une influence faible ou modérée sur le rythme des défrichements. En revanche, on constate que la construction de routes, le régime foncier et les politiques de mise en valeur des terres ont probablement une influence importante sur les surfaces de forêt abattues pour laisser place au pâturage. Il est recommandé d'autre part de restreindre les crédits à l'élevage dans les régions de frontière agricole à forte pluviométrie.

MacMillan Press, Londres, Royaume-Uni.

\section{Coopération forestière internationale: quelle voie adopter maintenant?}

Kiekens, J.P. et Byron, R.N.

Bien que la concertation internationale se soit bien améliorée depuis le Sommet mondial, il reste beaucoup à faire pour instaurer un aménagement rationnel des forêts à l'échelle mondiale. Cet article discute des tendances actuelles: pourparlers fréquents et traînant en longueur, suivis de peu d'actions; déclin de l'assistance officielle au développement pour les forêts; un cadre institutionnel international incomplet et incohérent; confiance croissante en des mécanismes hypothétiques du marché tels que 
la certification. Il conclut que la plupart des progrès en direction d'une gestion durable des forêts mondiales dépendront d'une bonne direction à l'échelon national et international. Les pays doivent définir et appliquer des politiques visant à remédier aux causes profondes de la dégradation et de la destruction des forêts, tant à l'intérieur qu'au dehors du secteur forestier. Un cadre international réellement susceptible de promouvoir une bonne gestion des forêts doit être élaboré grâce à des réformes profondes, telles qu'un renforcement de l'aide au développement pour les forêts, l'adoption de moyens opérationnels pour la coopération forestière internationale, la réforme des institutions forestières internationales, et l'adoption d'un cadre législatif approprié.

Eco-Decision 5: 7-12.

\section{La certification écologique des produits forestiers: problèmes économiques.}

Kiker, C.F. et Putz, F.E.

Avec le rythme croissant du déboisement dans le monde, on se demande de plus en plus si le marché peut jouer un rôle pour atténuer les effets écologiques et sociaux nuisibles des activités forestières. Le Forest Stewarship Council et d'autres organismes ont proposé des systèmes de certification écologique, grâce auxquels des produits par ailleurs très semblables sont considérés par les consommateurs comme des produits différents, dès lors qu'on leur fournit une information supplémentaire sur l'origine de ces produits. La certification assure le consommateur que ces produits ont été obtenus selon des pratiques qui répondent à des normes écologiques et sociales fondamentales. Pour que les systèmes de certification écologique soient viables et susceptibles d'alimenter le marché à longue échéance, les relations entre les éléments essentiels devront évoluer sur un plan économique et institutionnel. Comprenant des entreprises locales de gestion forestière, des organismes locaux de certification non officiels, des organisations non gouvernementales internationales, des marchés des bois et produits dérivés, le système de certification écologique transcende les forêts et les communautés locales pour se situer au plan des marchés internationaux. Conceptuellement, il consiste en une série de relations entre agents principaux. Ce document, 
après avoir développé le concept de la certification écologique, analyse les relations entre les nombreux acteurs et les relations entre ces acteurs et la forêt.

Ecological Economics, 1997, 20: 37-51.

\section{Evaluation de la capacité de recherche forestière en Afrique orientale et Australe.}

Kowero, G.S. et Spilsbury, M.J.

Les auteurs définissent une méthodologie pour évaluer la capacité de recherche, et l'appliquent à 19 institutions de 10 pays. Les indicateurs utilisés ne sont pas exhaustifs, mais ils sont utiles pour évaluer l'efficacité de la capacité de recherche existante. Les résultats soulignent à nouveau la nécessité de donner priorité au recrutement, à la formation et au perfectionnement de personnel, étant donné que la moitié seulement des chercheurs des institutions enquêtées ont une formation et une expérience de la recherche suffisantes. La gestion de la recherche demande également des mesures d'urgence. Environ 17 pour cent des institutions enquêtées affectent plus de $20 \%$ de leur budget de recherche à la transmission et à la diffusion des résultats de leurs recherches parmi les "groupes d'utilisateurs", et environ 28 pour cent du temps de travail du personnel est déclaré être affecté à cet effet. Cela soulève des questions sur la manière dont les priorités de recherche et les programmes sont formulés, et sur l'opportunité des recherches menées. Il y a une interaction importante entre institutions de la région, mais on ne voit pas très clairement comment cela peut se traduire en actions concertées coordonnées.

Journal of World Ressource Management 8: 159-82.

Influence des facteurs socio-économiques et des politiques sociales sur les systèmes de gestion de la production - Etude de cas dans l'industrie du bambou en Chine.

Maogong, Z., Maoyi, F., Belcher, B. et Ruiz-Pérez, M.

Depuis quelques années, l'industrie du bambou en Chine a connu un rapide développement à la suite des réformes et de la libéralisation, qui ont amené une série de politiques et de réglementations économiques favorables au développement. Entre 1981 et 1993, la surface couverte par des bambousaies 
s'est accrue plus vite que la surface de forêts du pays dans la même période. En 1996, la valeur de la production annuelle de produits primaires de bambou a atteint 0,9 milliard de \$EU. La valeur des exportations de produits manufacturés de bambou a été de 35 millions de \$EU en 1995. Etant donné que $93 \%$ des bambousaies dans les zones rurales sont de propriété collective et directement gérées par les agriculteurs, l'accroissement des rendements et des profits tirés ces bambous améliore notablement les revenus et le niveau de vie des populations rurales. L'industrie du bambou est par conséquent devenue un moyen important de lutte contre la pauvreté parmi la population rurale.

L'objet de cette étude est de promouvoir un développement durable du secteur du bambou en analysant le développement des industries du bambou dans le département d'Anji, province de Zhejiang. Cette analyse porte sur les données fondamentales de l'industrie, les méthodes et les déficiences potentielles, et explore les orientations et les méthodes appropriées pour poursuivre son développement.

Forestry Economics, Vol. 3 No. 1, 1998: 22-43.

Forestry Economics, No. 5, décembre 1997: 50-58 (Chinois).

\section{Les plantes ont-elles besoin de passeports? Etude socio- économique sur le rôle des arbres et autres plantes exotiques dans la province de Quang Tri au Vietnam. \\ Midgley, S.J., Byron, R.N., Chandler, F.C., Ha Huy Thinh, Tran Vo Hung Son et Hoang Hong Hanh.}

Une équipe multidisciplinaire a étudié le rôle et l'utilisation d'arbres exotiques et indigènes dans les systèmes d'économie domestique dans quatre villages représentatifs de trois écosystèmes distincts, dans la province de Quang Tri (Centre Vietnam). Tout en montrant que dans chaque cas les agriculteurs utilisent une grande variété d'arbres et autres plantes pour répondre à leurs divers besoins de subsistance et de revenus en argent, cette étude révèle la contribution essentielle des arbres exotiques. Là où le statut foncier est clair et la propriété des arbres non équivoque, on constate un enthousiasme général pour planter des arbres dans les quatre zones étudiées.

L'emploi de casuarinas en bande de protection côtière sur les dunes, en rideaux brise-vent autour des fermes et en plantations agroforestières, 
semble tout à fait positif selon tous les critères sociaux, écologiques et économiques. De même la plantation d'acacias a procuré d'importants bénéfices économiques et écologiques en brise-vent indispensables autour des plantations de caféier et de poivrier (espèces exotiques) sur les hautes terres près de la frontière du Laos, et en plantations mélangées sur les fermes des basses collines, formant un paysage en mosaïque. Des petites plantations d'eucalyptus pour la fourniture locale de bois de feu et de matériaux de construction sur les piémonts n'ont aucun effet social ou écologique nuisible perceptible, et elles constituent l'une des rares utilisations viables de ces terres tant pour les femmes que pour les hommes, tout en créant un substitut peu coûteux à l'extraction de bois de feu des rares forêts naturelles subsistantes.

Grâce à la concertation entre villageois, vulgarisateurs forestiers du gouvernement, programmes d'assistance d'ONG et autres usagers des terres, des essences appropriées sont choisies et des traitements sylvicoles mis au point, pour une amélioration appréciable du bien-être social et économique avec un minimum d'effets nuisibles sur l'environnement. Les agriculteurs concluent que, pourvu que les arbres répondent à leurs besoins, peu importe quel est leur pays d'origine.

CSIRO Forestry and Forest Products Technical Report No. 106. CSIRO, Canberra, Australie. $75 p$.

\section{Etude de prospective sur les produits forestiers autres que le bois dans la région Asie-Pacifique à I'horizon 2010.}

Mittelman, A.J., Lai, C.K., Byron, N., Michon, G. et Katz, E.

L'importance majeure des "menus produits" forestiers est de plus en plus reconnue à mesure que se développe l'information sur l'utilisation, le commerce et la gestion de ces produits des forêts autres que le bois. Cette étude présente une vue d'ensemble sur leur importance dans la région Asie-Pacifique, les tendances actuelles et futures probables de leur disponibilité et de leur gestion, leur importance pour les populations et pour l'économie, et les efforts entrepris pour réaliser un aménagement durable des forêts de la région.

Les données concernant les produits forestiers autres que le bois sont peu abondantes, souvent contradictoires et peu fiables, même pour des 
produits commerciaux importants tels que le rotin, le bambou et les résines. Pourtant ces produits procurent des revenus et des emplois à des centaines de millions, sans doute, d'habitants de la région. Un grand nombre de ces produits font l'objet d'un commerce, mais surtout ce sont des produits de première nécessité pour les habitants des régions forestières: aliments, épices, huiles comestibles, médicaments, fourrage, litière pour les animaux, engrais vert, matériaux de construction, ustensiles ménagers, fibres, ornementation et rituels.

La prospection biologique et l'utilisation croissante de médicaments et cosmétiques naturels amèneront probablement une expansion du commerce international de ces produits. La valeur des produits forestiers autres que le bois récoltés pourrait excéder celle du bois d'œuvre. Il y a d'autre part une demande croissante d'espèces protégées de flore et de faune comme trophées et comme médicaments, de la part d'un nombre croissant de consommateurs aisés de la région. Les effets écologiques nuisibles sur les forêts de la surexploitation d'espèces recherchées pourrait perturber les relations interspécifiques qui sont vitales pour maintenir l'intégrité et la stabilité des écosystèmes.

Une grande partie de nos connaissances sur la gestion durable des produits forestiers autres que le bois vient des connaissances techniques locales, qui sont le fruit d'une expérimentation séculaire menée par les populations autochtones traditionnelles. Jusqu'à une époque récente, on les avait largement ignorées. Les changements sociaux, culturels et économiques rapides associés à la modernisation ont une incidence profonde sur les populations forestières traditionnelles. La tendance générale est à un épuisement de ces ressources non ligneuses. Une organisation équitable des marchés pourrait pour l'avenir fournir des mécanismes importants pour assurer que les récolteurs et les transformateurs de ces produits reçoivent un juste prix pour des produits provenant de sources rationnellement aménagées et exploitées.

FAO Regional Office for Asia and the Pacific (Bureau régional de la FAO pour l'Asie et le Pacifique), Bangkok, Thaïlande. $65 p$. 
Les peuplements d'Okoumés au Gabon. Leur dynamique et croissance en zone côtière.

Nasi, $R$.

La mesure et le suivi annuel, entre 1987 et 1994, de 34 parcelles d'âge connu (représentant 22 ha et près de 14000 arbres) établies dans des peuplements d'Okoumé de la zone côtière du Gabon permettent de préciser la dynamique de ces formations végétales paucispécifiques. Ces peuplements sont issus de colonisation à des vitesses variables de savanes ou de défrichements culturaux en l'absence de feux. Leur composition floristique varie avec l'âge, mais toutes présentent un fonds floristique commun d'une dizaine d'espèces qui constitue plus de $90 \%$ des individus recensés. La surface terrière augmente et la densité diminue avec l'âge pour se stabiliser autour de valeurs "limites" vers 40-45 ans. La mortalité, très forte dans les jeunes parcelles, diminue avec l'âge. Elle affecte essentiellement les tiges de faible diamètre appartenant à l'étage dominé. La mort de dominants âgés constitue un phénomène rare ( $1 \%$ des morts et $0,06 \%$ de l'ensemble des tiges), même pour des parcelles âgées de 60 ans. Les mesures d'accroissement en circonférence et surface terrière montrent que l'essentiel de la croissance est le fait du peuplement d'Okoumés dominants. En fonction des valeurs de croissance obtenues, il faut environ 75 ans pour produire un Okoumé "moyen" acceptable de $70 \mathrm{~cm}$ de diamètre dans les conditions d'Oyane. Les résultats sont comparés avec ceux obtenus dans des formations végétales similaires dans le centre du Gabon par le projet ECOFAC.

Bois et Forêts des Tropiques, No. 251, 1997, p. 5-26.

Les marchés pour les produits forestiers autres que le bois dans la zone de forêt dense du Cameroun. In: Doolan, S. (sous la direction de) Forêts denses d'Afrique et conservation de la biodiversité. Actes de la Conférence de Limbe, 17-24 janvier 1997, 128-33.

Ndoye, O. et Ruiz-Pérez, M.

De nombreux habitants des zones rurales sont tributaires des produits forestiers autres que le bois pour leur subsistance et leurs revenus. L'urbanisation croissante - résultat de l'exode rural - est un facteur important de développement des marchés locaux de ces produits. Ce 
document étudie les marchés locaux de la zone de forêt dense du Cameroun, et les intermédiaires qui facilitent la coordination - ou l'adaptation - de l'offre et de la demande de produits forestiers en offrant des débouchés aux agriculteurs et en garantissant aux consommateurs une source locale d'approvisionnement de ces produits. Les contraintes de comportement et les méthodes commerciales habituelles des intermédiaires ne sont pas toujours connues, notamment dans une ambiance de crise économique. Les négociants en produits forestiers ne travaillent pas toujours avec un seul produit. Cette stratégie leur permet de soutenir un produit par l'autre, autrement dit la marge bénéficiaire obtenue sur un produit peut servir à soutenir d'autres produits forestiers (achat, stockage, transformation). La quantité de produits forestiers commercialisés dans la zone de forêt dense du Cameroun est importante. D'autre part, les marges bénéficiaires obtenues par les négociants varient entre 16\% (pour Dacryodes edulis) et 30,4\% (pour Irvingia gabonensis) sur le prix de vente. En outre, les marges commerciales obtenues par les négociants qui achètent et vendent des produits de Dacryodes edulis, Ricinodendron heudelotii et Irvingia gabonensis sont plus élevées que les salaires minimum sur la plupart des marchés. Cette étude confirme donc le rôle des produits forestiers autres que le bois comme source d'emploi et de revenus pour ceux qui en font le commerce, et indique la nécessité de développer ces marchés.

Union Européenne/Projet Mont Cameroun/ DfID/EARTHWATCH, Londres.

\section{Les marchés pour les produits forestiers autres que le bois dans la zone de forêt dense du Cameroun.}

Ndoye, O., Ruiz-Pérez, M. et Eyebe, A.

De nombreux habitants des zones rurales des régions tropicales sont tributaires des produits forestiers autres que le bois pour leur subsistance et leurs revenus. Les marchés locaux jouent un rôle important en permettant aux ménages vivant en forêt de tirer une part importante de leurs revenus en argent de la vente de produits forestiers autres que le bois. L'urbanisation croissante - résultat de l'exode rural - est un facteur important de développement des marchés locaux de ces produits.

Ce document étudie les marchés locaux et les intermédiaires qui facilitent la coordination - ou l'adaptation - de l'offre et de la demande de 
produits forestiers en offrant des débouchés aux agriculteurs et en garantissant aux consommateurs une source locale d'approvisionnement de ces produits. Il présente les résultats d'une étude qui analyse les quatre principaux produits forestiers autres que le bois qui sont vendus dans la zone de forêt dense du Cameroun (Dacryodes edulis, Irvingia spp, Cola acuminata et Ricinodendron heudelotii). L'étude a permis de constater l'importance des quantités de produits forestiers commercialisés, qui représentent au moins 1,75 million de \$EU pour le premier semestre de 1995. Plus de 1100 commerçants, principalement des femmes, sont engagés dans la distribution de produits forestiers. D'autre part, les marges bénéficiaires obtenues par les négociants varient entre 16\% (pour Dacryodes edulis) et $30 \%$ (pour Irvingia spp) sur le prix de vente. Cette étude confirme donc le rôle des produits forestiers autres que le bois comme source d'emploi et de revenus non seulement pour ceux qui les récoltent mais aussi pour ceux qui en font le commerce, et indique la nécessité et la possibilité de développer ces marchés.

ODI Rural Development Forestry Network Paper 22c. ODI, Londres, Royaume-Uni. 20p.

Bénéfices non commerciaux des forêts: méthode de modélisation pour l'orientation des interventions au Mozambique. In: Actes d'un colloque international sur les bénéfices non commerciaux des forêts, Edimbourg, 24-28 juin 1996.

Nhantumbo, I., Dent, J.B., Kowero, G.S. et McGregor, M.J.

L'aménagement forestier s'intéresse normalement surtout aux produits forestiers commercialisables, par opposition aux produits non commercialisables et aux bénéfices non marchands tels que prévention de l'érosion, valeurs esthétiques et culturelles traditionnelles, maintien de la biodiversité, conservation de la flore et de la faune sauvages, et autres bénéfices incorporels. Cette situation résulte du fait que les biens marchands sont inclus dans la comptabilité nationale en tant que contribuant au PIB. Les moyens possibles, et encore contestés, susceptibles d'intervenir pour l'analyse des impacts macroéconomiques des variables écologiques sont notamment la création de la comptabilité écologique (Resource Environmental Accounts) et du Produit intérieur 
net écologique ajusté (Environmental Adjusted Net Domestic Product), et autres approches telles que changements de politiques macroéconomiques et programmation linéaire.

La planification de l'aménagement forestier exige une intégration de toutes les ressources en y incluant les utilisations potentielles par différents groupes sociaux au niveau national et international à moyen ou long terme. L'association des secteurs tant officiels que non officiels à la planification et l'application de mesures destinées à protéger l'environnement au niveau national dépendent de la valeur que chacun attribue aux ressources. Cependant, la méthode la plus employée pour l'évaluation de l'environnement, l'Evaluation contingente (Contingent Valuation), rencontre encore beaucoup de scepticisme en ce qui concerne la fiabilité de ses résultats. C'est pourquoi des problèmes méthodologiques surgissent de plus belle lorsqu'on tente d'analyser l'impact probable de politiques ou stratégies environnementales futures possibles au niveau macroéconomique dans une situation où l'on dispose de peu de données, et que les groupes visés n'ont que peu ou pas d'information sur les biens écologiques. D'autres difficultés concernent le calcul de coefficients et le choix du niveau approprié de regroupement.

Dans cette recherche, un cadre de modèles de programmation mathématique à objectifs multiples incorporant les préférences des agriculteurs, les objectifs et priorités environnementaux régionaux et nationaux est élaboré en vue de déterminer l'impact de l'utilisation de produits forestiers commercialisables sur les bénéfices non marchands des forêts. L'incorporation de ces derniers dans le modèle fournit la base d'un système d'aide à la décision puissant pour intervenir sur les orientations.

\section{Estimation de la vitalité des gaulis de pin sylvestre, Pinus sylvestris, en Carélie russe.}

Oreshkin, D.G., Skovsgaard, J.P. et Vanclay, J.K.

Les auteurs proposent une nouvelle méthode pour estimer la vitalité ou le potentiel de croissance de gaulis de pin sylvestre (Pinus sylvestris L.), à partir de la hauteur, du diamètre et de l'accroissement en hauteur. Une méthode en deux étapes a été utilisée pour déterminer l'indice de vitalité. On établit des courbes de régression des logarithmes de la hauteur, du 
diamètre et de l'accroissement en hauteur en fonction de l'âge, pour les ajuster compte tenu de la large gamme d'âges présente dans les données (environ 10000 tiges d'âges compris entre 4 et 50 ans). Ensuite une analyse de composantes principales a été utilisée pour obtenir des coefficients qui, à leur tour, ont été normalisés sur chaque axe pour fournir un indice de vitalité gradué en écarts types. Cette échelle normalisée permet d'évaluer le rang d'un individu dans la population, et attire l'attention sur les individus aberrants éventuels. L'emploi de résidus ajustés en fonction de l'âge assure que l'estimation est indépendante de l'âge, et stable sur une large gamme d'âges. La première composante principale indique si une tige est relativement haute (coefficient de pondération $=0,50$ ), de fort diamètre (coefficient 0,5 ) ou de croissance rapide (coefficient 0,5 ) pour son âge. La plus grande partie de l'information est contenue dans la première composante principale, mais la deuxième, qui rend compte d'environ $10 \%$ de la variance, présente une certaine utilité comme indicateur d'une "accélération" due à un changement de conditions. Les mesures de la vitalité qui en découlent se sont avérées utiles pour la recherche et l'aménagement dans les forêts de pins sèches à lichens et mousses de Carélie russe, mais elles sont spécifiques de cette essence, de cette localité et de cet écotype. De nouvelles recherches et des données spécifiques de la station seront nécessaires pour adapter la méthode à d'autres situations.

Forest Ecology and Management 97: 147-53.

Situation, tendances et scénarios futurs pour la conservation des forêts, notamment des aires protégées, dans la région Asie-Pacifique. Etude de perspectives forestières dans la région Asie-Pacifique, document de travail.

Paine, J.R., Byron, N. et Poffenberger, M.

Les auteurs cherchent à évaluer les perspectives d'avenir pour la conservation des forêts, notamment des aires protégées, dans la région Asie-Pacifique à l'horizon 2010, selon trois scénarios supposant:

- La poursuite du niveau actuel d'actions et de politiques concernant l'environnement ("statu quo");

- Des campagnes soutenues en faveur de l'environnement, et un rôle accru pour la conservation par rapport à la situation actuelle; 
- Des changements négatifs dans les politiques et les actions relatives à la conservation.

Les populations locales permettront aux forêts de se maintenir si elles estiment que la permanence des forêts est plus bénéfique (c'est-à-dire crée des revenus plus élevés ou a des valeurs culturelles ou sociales) que leur disparition. Sinon, les forêts seront défrichées. Les politiques officielles de conservation des administrations forestières sont inadaptées, voire directement contredites par les politiques hors du secteur forestier. La conservation de la biodiversité et la lutte contre le déboisement ne peuvent être résolues qu'en considérant les problèmes des communautés tributaires des forêts dans un contexte plus large, tel que mouvements de population et accès à la terre.

De nombreux pays d'Asie, en conséquence, ont entrepris de formuler des politiques qui prévoient l'association des communautés à la gestion des forêts domaniales de conservation. Ces nouvelles approches coopératives, bien que largement appuyées par les organismes donateurs, restent imparfaites. Seul un faible pourcentage des forêts du domaine public en Asie font officiellement l'objet d'une cogestion. Durant des décennies les communautés locales ont été considérées comme une menace pour la biodiversité des forêts et pour la production forestière commerciale. Les associer officiellement à la gestion et leur conférer une autorité et des droits est un changement radical d'orientation. La négociation d'accords de gestion conservatrice entre communautés, services forestiers et autorités locales représente une tâche colossale. Les communautés, et les femmes, dépourvues de pouvoir politique devront être effectivement représentées à mesure que de nouveaux accords de gestion des forêts seront formulés en vue de leur conservation.

Bureau régional de la FAO pour l'Asie et le Pacifique, Bangkok, Thaïlande. 74 p.

\section{Catalyser la régénération des forêts naturelles sur les terres tropicales dégradées.}

Parrotta, J.A., Turnbull, J.W. et Jones, N.

Le défrichement des forêts, leur dégradation du fait des activités humaines et le déclin de la productivité des sols dû à des pratiques agricoles impropres sont des problèmes majeurs dans les tropiques. La restauration 
de la santé et de la productivité des écosystèmes repose généralement sur l'abandon de la terre et sur la succession de végétation qui s'ensuit. Depuis peu on s'intéresse à des formules d'aménagement susceptibles d'accélérer la restauration de la végétation et de rétablir sa productivité, sa biodiversité et autres valeurs. Le recours à la plantation d'arbres pour catalyser la restauration des forêts et des sols dégradés dans les tropiques a fait l'objet d'un colloque qui s'est tenu en juin 1996 à Washington, D.C. Les conclusions et les suggestions de recherche future pour développer des formules d'aménagement appropriées sont rapportées dans le présent document. Il est manifeste que les plantations peuvent faciliter la succession forestière dans leur sous-étage grâce à la modification des conditions tant physiques que biologiques de la station. Des changements dans l'éclairement, la température et l'humidité à la surface du sol permettent la germination et le développement de semences apportés par les animaux et autres vecteurs à partir des relictes forestières voisines. Il faut étudier et mettre au point des modes d'aménagement appropriés pour aider ce processus, en tenant compte des réalités socio-économiques, des priorités du développement et des objectifs de conservation.

Forest Ecology and Management 99: 1-7

Evaluation et suivi des ressources de forêts et d'arbres. In: Actes du Xlème Congrès forestier mondial, Antalya (Turquie), 13-22 octobre 1997, Volume 1, 17-29.

Persson, R. et Janz, K.

On se préoccupe de plus en plus, au niveau national et international, d'avoir une meilleure information sur les ressources forestières. Des demandes apparaissent fréquemment aujourd'hui pour de nouveaux types d'information (concernant par exemple la diversité biologique, les produits forestiers autres que le bois, la qualité des forêts). Toutefois, la base conceptuelle et méthodologique pour répondre à ces nouvelles demandes est souvent insuffisante. En outre, pour répondre à toutes les nouvelles questions il faudra des fonds qui ne seront pas disponibles dans un avenir prévisible.

Au cours des dernières décennies de grands progrès ont été accomplis dans les méthodes et techniques d'inventaire (par exemple dans le domaine de la télédétection et des SIG). Pourtant, il y a de sérieuses 
déficiences dans l'information sur les ressources forestières, tant dans les pays développés que dans les pays en développement. Les conclusions de l'évaluation des ressources forestières de 1990 de la FAO indiquaient que dans les pays en développement seuls $14 \%$ des surfaces boisées étaient couverts par des inventaires de fiabilité élevée, tandis que $43 \%$ étaient couverts par des inventaires de faible fiabilité. Dans les pays développés, qui dans ce contexte particulier incluent les pays en transition, la qualité de l'information forestière varie largement selon les pays, et elle comporte de sérieuses lacunes.

L'Evaluation des ressources forestières entreprise par la FAO utilise deux approches. La première, qui fournit une information à l'échelle d'un pays, s'appuie principalement sur des données nationales. Comme il y a des lacunes dans ces données nationales, les résultats de l'évaluation présentent naturellement aussi des déficiences. Une meilleure information dans l'évaluation exige en premier lieu des inventaires nationaux améliorés.

Les estimations de la FAO pour 1995 montrent qu'environ 27\% de la superficie terrestre du globe sont couverts de "forêt". Cette forêt renferme en moyenne 110 mètres cubes de bois par hectare. Chaque année la superficie de forêt dans les pays en développement diminue de quelque 13 millions d'hectares, tandis que dans les pays développés (Russie exclue) elle s'accroît de 2 millions d'hectares.

Une nouvelle Evaluation des ressources forestières est en cours, et elle sera publiée en l'an 2000. La situation de l'information dans les pays s'est dégradée plutôt qu'améliorée depuis l'évaluation précédente de 1990. Le travail fait pour l'évaluation de 2000 devrait être utilisé comme outil pour améliorer les capacités nationales, de sorte que la plupart des pays aient une meilleure information pour servir de base à l'aménagement de leurs propres forêts et que, accessoirement, ils puissent fournir une bonne information pour l'évaluation de 2010. Bâtir une telle capacité prend du temps. Et c'est au niveau national et local qu'il peut être fait le meilleur usage des inventaires forestiers. 


\section{Observation suivie des gains en fixation du carbone associés à} un projet d'exploitation forestière à faible impact en Malaisie.

Pinard, M.A. et Putz, F.E.

Le Projet d'exploitation forestière à faible impact, qui est un projet pilote de compensation des émissions de CO2, a été lancé en 1992 avec l'octroi par une compagnie de production d'électricité à un concessionnaire forestier de fonds pour mettre en œuvre des directives d'exploitation à faible impact dans une forêt à diptérocarpacées. Le principe de base de cette compensation est que, lorsque les dommages d'exploitation sont réduits au minimum, davantage de carbone est retenu dans la biomasse des arbres restants et que, du fait que les dommages au sol sont réduits, la productivité de la forêt demeure élevée. Pour estimer le gain en carbone associé à l'application des directives d'exploitation, on a élaboré un programme de suivi qui comporte 1) des études de terrain pour mesurer les stocks et les flux de carbone; 2) un modèle informatique de dynamique du carbone dans la forêt pour simuler diverses combinaisons d'intensité de coupe et de dommage; 3 ) un modèle de projection pour calculer le bilan du carbone sur la durée du projet.

Soixante-quinze pour cent du carbone stocké dans la forêt se trouve dans la biomasse, et sur cette part 59\% l'est dans des grands arbres (>60 cm de diamètre); en conséquence, il est essentiel de disposer d'estimations fiables des variables relatives aux grands arbres pour l'estimation des gains de carbone. Il est recommandé d'employer des méthodes allométriques pour estimer la biomasse souterraine plutôt que des méthodes d'échantillonnage par trous, en raison du coût moindre pour obtenir des estimations précises de la biomasse racinaire. Des analyses de sensibilité des variables employées dans le modèle de simulation permettent de penser que le maintien de la productivité de l'écosystème a une grande influence sur le stockage à long terme du carbone dans la forêt. Les projections de différences dans la quantité de carbone fixée entre exploitation à faible impact et exploitation classique reposent sur des hypothèses concernant la mortalité des arbres, la croissance et le recrutement; des données publiées pour des sites comparables en Malaisie sont probablement appropriées pour estimer le rétablissement de la forêt après exploitation de type classique mais non à faible impact. On escompte que la poursuite du travail de terrain fournira les données nécessaires pour évaluer les hypothèses des modèles.

Mitigation and Adaptation Strategies for Global Change 2: 203-215. 
Arrêter une cible mobile: production soutenue, population et forêts. Document présenté à Institut Pertanian Bogor (IPB) Université de Göttingen.

Prabhu, R. et Vanclay, J.K.

La production soutenue, dans le contexte du développement et de l'aménagement forestier, est une notion définie par des humains. Etant donné que les besoins humains changent dans l'espace et dans le temps, il en sera de même des biens et services dont on attend une production soutenue. Une grande partie de la recherche du CIFOR vise à fournir une meilleure connaissance des questions essentielles qui gouvernent l'aménagement des forêts, et de la manière dont elles peuvent être influencées pour fournir des solutions durables. Cet exposé a pour objet de présenter deux approches complémentaires pour mieux appréhender les questions essentielles et la dynamique de l'aménagement forestier. Dans la première approche, le CIFOR cherche à identifier les questions essentielles par des critères et indicateurs de la gestion forestière durable, avec pour objectif de développer de meilleures méthodes d'évaluation. La deuxième approche consiste à modéliser les interactions entre humains et forêts. Ces deux approches illustrent la nécessité de développer des outils qui soient suffisamment généralisables pour être utiles à un grand nombre de gens, mais aussi suffisamment adaptables aux conditions locales pour avoir une utilité pratique.

Séminaire sur la stabilité des lisières forestières, IPB, Bogor, Indonésie, 14-17 avril 1997. 7p.

Méthodes de recherche pour l'exploitation forestière à faible impact: résultats d'un colloque. Rapport sur le Séminaire de formation à l'exploitation forestière à faible impact et à l'aménagement des forêts naturelles, tenu du 14 au 27 juillet 1996 à Bogor et au Kalimantan Oriental, Indonésie. 84 p.

Putz, F.E., Elias, Sist, P., Dykstra, D.P. et Heinrich, R.

En juillet 1996, avec ue assistance de la FAO, de l'USAID et de l'USDA Forest Service, le CIFOR a organisé son premier Séminaire de formation en recherche internationale sur l'exploitation forestière à faible impact et l'aménagement des forêts naturelles. Les participants venaient de dix pays et représentaient des disciplines allant de la sylviculture et de l'hydrologie 
à la biologie de la faune sauvage. Tout au long du séminaire, des exercices de terrain étaient intégrés avec un enseignement en salle, au début dans la plantation forestière expérimentale près du siège du CIFOR, et ensuite dans une concession d'exploitation industrielle du Kalimantan oriental. Les participants ont également mené une journée de recherche sur certains aspects de l'aménagement forestier. Leurs rapports écrits constituent le fond de cette publication, et ont été regroupés par sujet. Le premier groupe comprend sept articles sur le tassement du sol et l'érosion; le deuxième comprend dix articles, l'un sur les dommages aux arbres et le reste sur la densité ou sur la croissance des arbres dans différentes situations et avec différentes conditions.

\section{Expériences pratiques et priorités de recherche en sylviculture des forêts naturelles en Amérique tropicale. Actes du séminaire-atelier tenu à Pucallpa, Pérou du 17 au 21 juin 1996.} Sabogal, C., Camacho, M. et Guariguata, M. (sous la direction de).

Cette publication rassemble les exposés présentés au séminaire-atelier qui s'est tenu à Pucallpa (Pérou) du 17 au 21 juin 1996, avec l'appui du CIFOR, du CATIE et de l'INIA, et qui avait pour objet d'associer des chercheurs et des techniciens à des expériences directes dans le domaine de la sylviculture des forêts naturelles de la région, et ainsi améliorer la collaboration et permettre des échanges entre personnes de différentes institutions qui travaillent dans ce secteur. Cette rencontre fait partie d'une série d'actions visant à promouvoir les connaissances en sylviculture, la recherche et les expériences, en tant qu'élément essentiel de l'aménagement des forêts d'Amérique tropicale.

Il y a été présenté trois conférences magistrales et 12 exposés, dans lesquels ont été abordées les expériences concrètes de recherche sylvicole dans la région Amérique Latine-Caraïbes en général et en Amazonie péruvienne et colombienne en particulier, les différents traitements sylvicoles, les impacts et les effets de l'exploitation de reboisements dans des zones spécifiques du Costa Rica, du Pérou et du Guatemala, et l'exploitation de produits forestiers autres que le bois dans un but de diversification de la production.

Publicación Especial CIFOR/CATIE/INIA. Turrialba, Costa Rica. $236 p$. 
Techniques pour répondre aux enjeux de l'aménagement des forêts au 21ème siècle.

Sayer, J.A., Vanclay, J.K. et Byron, N.

La technique aidera à répondre aux enjeux de l'aménagement forestier au 21 ème siècle. Certains de ces enjeux comporteront le passage de l'exploitation des forêts naturelles à des plantations artificielles là où elles auront un avantage comparatif, une transformation plus efficace des bois moins dépendante des caractéristiques de la matière première, une demande accrue, de meilleures techniques d'information pour aider la prise de décisions, et des formules plus variées pour la conservation de la biodiversité. La définition de l'aménagement durable variera dans le temps et dans l'espace à mesure de l'évolution des espérances et aspirations de la société, de sorte qu'il n'y a pas de "formule magique" pour assurer la pérennité de la forêt. Cependant, le progrès dans cette voie pourra être facilité par une approche systématique de l'aménagement forestier englobant le cycle habituel de planification: formulation des objectifs, définition d'une stratégie, planification, exécution, contrôle et réévaluation. Cela demande une bonne compréhension de chaque situation particulière. Les aménagistes doivent disposer d'une bonne évaluation des ressources et de systèmes d'appui à la décision; ils doivent favoriser la participation de tous les ayants droit aux décisions et aux coûts et bénéfices, et mettre en place des procédures efficaces pour résoudre les conflits. Dans un système approprié, des progrès techniques tels que de meilleurs équipements mécaniques et de nouveaux instruments peuvent apporter une certaine amélioration, mais ils ne sauraient à eux seuls assurer la durabilité de l'aménagement. Les techniques d'aménagement importantes à cet égard sont celles qui favorisent une meilleure communication entre les parties prenantes et qui permettent de prendre des décisions informées prenant en compte tous les facteurs depuis les gènes jusqu'à l'écosystème. Cela reste un enjeu important pour les gestionnaires forestiers dans leur quête du rendement soutenu de leurs forêts.

Commonwealth Forestry Review 76: 162-70. 
Politiques forestières en Amérique Centrale: analyse des contraintes au développement du secteur forestier.

Segura, O., Kaimowitz, D. et Rodríguez (sous la direction de).

Cet ouvrage a pour objet de reconnaître les contraintes qui freinent le développement durable du secteur forestier dans les sept pays de l'isthme centraméricain. Il présente des études nationales, fruit d'une recherche et d'une consultation sur les politiques forestières de chaque pays, réalisées par des chercheurs nationaux. Pour chacun des pays il décrit la situation du secteur forestier, la politique forestière en vigueur et les politiques et contraintes d'autres secteurs qui ont une incidence sur les forêts. Enfin il présente une synthèse régionale des études.

IICA-Holanda/LADERAS, San Salvador, Salvador. 335p.

\section{Le projet STREK.}

Sist, P. et Bertault, J.G.

STREK est un sigle pour Silvicultural Techniques for the Regeneration of logged over forests in East Kalimantan (Techniques sylvicoles pour la régénération des forêts exploitées au Kalimantan oriental), projet indonésien. Le Ministre des Forêts d'Indonésie et le CIRAD-Forêt en étaient les maîtres d'œuvre, tandis que la société étatique indonésienne INHUTANI I était l'organe d'exécution sur le terrain. La zone d'étude était située dans la province indonésienne de Kalimantan Timur (Kalimantan oriental). La concession d'INHUTANI I est couverte en majorité de forêt de plaine mélangée à diptérocarpacées, primaire et exploitée. Deux sites de 1000 hectares chacun furent choisis. Sur le premier site (RKL 1), exploité en 1978-1979, on mit en place six parcelles de 4 hectares chacune. Sur le deuxième site (RKL 4), couvert de forêt primaire jusqu'à 1991, 12 parcelles de 4 hectares chacune furent délimitées. Sur toutes les parcelles, tous les arbres de $10 \mathrm{~cm}$ et plus de diamètre furent mesurés, numérotés et cartographiés à l'échelle 1:200. D'autres caractéristiques physiques importantes telles que la topographie et les sols furent également évaluées dans chaque parcelle. Deux traitements sylvicoles différents (éclaircie chimique) furent testés dans RKL 1. Des techniques d'exploitation à faible impact furent appliquées et comparées avec les techniques classiques dans RKL 2. Quatre traitements furent définis: deux à faible impact, avec deux différentes limites de 
diamètre $(>50 \mathrm{~cm}$ et $>60 \mathrm{~cm})$, un classique et un témoin non exploité. Les techniques d'exploitation à faible impact comportaient un tracé du réseau de pistes de débardage avant la coupe, un abattage dirigé, et un délianage pratiqué trois mois avant la coupe.

Cahier FAO: Exploitation Forestière 7(1): 4

Succès de la régénération et croissance intiale des peuplements forestiers. Choix de communications d'une Conférence IUFRO tenue en juin 1996 à Copenhague.

Skovsgaard, J.P. et Vanclay, J.K. (sous la direction de)

Dix communications extraites des actes de la conférence ci-dessus, présentant les résultats de travaux plus complets sur les divers aspects de la régénération et de la croissance initiale des peuplements. Ce thème a été discuté dans les grandes lignes au cours de la conférence, en englobant les aspects théoriques et l'application de la sylviculture des peuplements artificiels et de peuplements "quasi naturels", les forêts naturelles et artificielles dans les zones tropicales, tempérées et boréales. Les articles présentés dans ce numéro spécial de Forest Ecology and Management reflètent cette perspective générale tant par les essences que par les régions considérées.

Numéro spécial de Forest Ecology and Management 97: 93-205.

Mise au point de techniques de marqueurs génétiques biochimiques pour Shorea spp et autres essences forestières tropicales.

Sudarmonowati, E., Hartati, N.S. et Siregar, U.J.

Deux types de matériels, six compositions de tampon d'extraction et trois systèmes de tampon électrophorétique ont été étudiés pour établir des procédures optimales en vue d'obtenir une bonne résolution de 14 systèmes d'enzymes dans 12 espèces de Shorea, famille des Diptérocarpacées. Treize systèmes d'enzymes ont pu être détectés dans S. seminis et S. parvifolia, 10 dans S. laevis, S. leprosula, S. selanica, S. acuminata, S. gibbosa, S. palembanica et S. pauciflora, 7 dans S. paquetiana et 4 dans $S$. johorensis. L'emploi d'un tampon d'extraction $\mathrm{W}$ en combinaison avec des systèmes tampon électrophorétiques MC a montré que les meilleurs résultats obtenus 
avec des brindilles étaient presque les mêmes qu'avec des feuilles, et qu'une meilleure résolution de certains systèmes d'enzymes tels que PER, PGI, $\mathrm{SDH}$ et MDH étaient obtenue avec des feuilles. Les résultats fournis par cette étude pourront être utiles pour de nouvelles études sur divers aspects tels qu'évaluation de la diversité génétique de Shorea spp et amélioration génétique.

Annales Bogorienses, 1997, 5(1): 1-14.

\section{Déboisement, moyens de subsistance et conditions préalables de l'aménagement forestier dans le département d'Olancho, Honduras.}

Sunderlin, W.D.

L'accroissement du cheptel bovin national au Honduras contribue à un déboisement rapide et anarchique. Des recherches de terrain ont été conduites dans le département d'Olancho afin de mieux appréhender ce problème et évaluer les perspectives d'intérêt de la population locale à la protection des forêts. Un regain récent de la rentabilité de l'élevage bovin est de mauvais augure pour les forêts, mais en compensation trois facteurs pourraient en définitive fournir le fondement d'un aménagement forestier communautaire. Premièrement, les habitants de la région ont un sentiment de l'utilité économique et écologique des forêts plus fort qu'on ne pourrait le supposer au vu de la progression rapide du déboisement. Ensuite, le bois est localement une importante source de revenus, et il pourrait donc y avoir une incitation latente à maintenir cette ressource à long terme.Troisièmement, certains habitants ne se tournent pas vers l'élevage, en dépit de sa rentabilité, peut-être parce qu'ils tirent leurs moyens d'existence de la vente de bois. Les politiques instaurées en 1992 sapent ces incitations naissantes à la conservation des forêts. Le déboisement anarchique peut être freiné par des réformes de politique qui permettraient aux petits propriétaires de conserver et aménager leurs ressources à long terme.

Agriculture and Human Values, 1997, 14(1): 373-86. 
Méthologie pour la mesure a posteriori de la participation des populations pauvres à la foresterie sociale: un exemple de Java, Indonésie.

Sunderlin, W.D.

L'un des objectifs clefs de la foresterie sociale est d'associer les plus démunis aux bénéfices des projets. Il est possible de mesurer le degré d'accomplissement de cet objectif en rassemblant des données socioéconomiques avant et après l'exécution du projet. Cette approche ne peut être appliquée pour les nombreux sites où l'on n'a pas recueilli de données au préalable. Cet article propose une méthodologie pour évaluer le degré de participation des tranches pauvres de la population en utilisant uniquement des données a posteriori. Une analyse longitudinale est faite par approximation grâce à l'emploi de variables socio-économiques "d'évolution lente" et d'une régression logistique. Cette méthodologie est illustrée par des données sur le Programme de foresterie sociale de Java.

Agroforestry Systems 37: 297-310.

\section{Culture itinérante et déboisement en Indonésie: comment éviter la confusion dans les discussions.}

Sunderlin, W.D.

Le rôle joué par la culture itinérante dans le déboisement en Indonésie est un domaine très controversé. Certains affirment que les systèmes culturaux sont la principale cause de la disparition du couvert forestier, tandis que d'autres soutiennent que, loin d'être dommageables, ils constituent un moyen essentiel pour la conservation et l'aménagement durable des forêts subsistantes. C'est un dialogue de sourds, car chacun se réfêre à des systèmes agricoles différents aux extrémités opposées de ce qu'on pourrait appeler le "continuum d'agriculture forestière". On a récemment progressé en clarifiant la signification de certains termes, mais le débat reste confus. Afin de mieux appréhender les causes et l'importance des changements dans le couvert forestier en Indonésie, il convient d'identifier clairement les différents agents qui interviennent dans les forêts, et aussi de définir des termes et des concepts fondamentaux tels que "forêt", "déboisement", "dégradation", "causalité". A partir de ces définitions on pourra alors effectuer une analyse des changements du couvert forestier dans le temps.

ODI Rural Development Forestry Network Network Paper 21b. ODI, Londres, Royaume-Uni. 20 p. (En Anglais, Français et Espagnol). 
Organisations de pêcheurs et modes de cogestion: le cas de la baie de San Miguel aux Philippines.

Sunderlin, W.D. et Gorospe, M.L.G.

De récents écrits ont affirmé que la gestion des pêches peut être améliorée grâce à une réglementation conjointe par les organismes officiels et les utilisateurs des ressources, et une délégation partielle de l'autorité de gestion du gouvernement aux organisations de pêcheurs. Les Philippines semblent présenter un cadre institutionnel optimal pour l'instauration d'une cogestion des pêcheries. Le gouvernement a promulgué une législation pour aider les organisations de pêcheurs à jouer un rôle accru dans la gestion des pêches, et on a assisté à une prolifération d'organisations de pêcheurs intéressées à assumer de plus grandes responsabilités dans la gestion de cette ressource. Le cas de la baie de San Miguel montre une situation dans laquelle deux modes parallèles de cogestion sont apparus. Le mode formel procède en grande partie de l'initiative du gouvernement, et est pluraliste, tandis que le mode informel est né de l'initiative des organisations de pêcheurs et de l'action civile, et est orienté vers les intérêts des petits pêcheurs. Une cogestion efficace à long terme exige avant tout de régler les conflits possibles entre les deux et d'éviter la marginalisation des petits pêcheurs, et d'intégrer les efforts des deux modes en présence.

Human Organization 56: 333-43.

\section{Une économie et une politique pour Imperata.}

Tomich, T.P., Kuusipalo, J., Menz, K. et Byron, N.

Les gouvernants - ou qui que ce soit d'autre - devraient-ils se soucier des millions d'hectares de prairies d'Imperata? La réponse dépend du bilan entre coûts de conversion à d'autres utilisations et gains nets produits en matière de croissance économique, lutte contre la pauvreté, et protection de l'environnement. La première section, sur l'économie d'Imperata, dresse le cadre analytique pour traiter cette question et s'inspire de la littérature plus générale sur l'économie du développement pour se demander si croissance et lutte contre la pauvreté sont des objectifs contradictoires ou complémentaires. Bien qu'on ait peu d'éléments pour le prouver, les auteurs avancent l'opinion que l'agroforesterie, faisant appel 
aux petits paysans, pourrait procurer la même croissance économique, avec un meilleur allégement de la pauvreté, que des projets forestiers à grande échelle. Il n'y a toutefois pas de substitut à l'évaluation de projets pour des situations spécifiques. La deuxième section, sur les politiques en matière d'Imperata, examine si les distorsions de politiques et les failles des marchés constituent un motif suffisant pour une intervention directe visant à promouvoir la plantation d'arbres sur les prairies d'Imperata. Des estimations des valeurs attribuées à la fixation de carbone pour atténuer le réchauffement mondial sont présentées pour une agroforesterie à base d'Acacia mangium et d'hévéa. La conclusion résume le programme des recherches sur les politiques et examine l'opportunité et la viabilité d'interventions d'orientation pour promouvoir la fixation du carbone grâce à la conversion de prairies d'Imperata en systèmes arborés.

Agroforestry Systems 36: 233-61.

La végétation de l'Australie. In: J.C. Doran et Turnbull, J.W. (sous la direction de) Arbres et arbustes Australiens: espèces convenant pour la restauration des sols et les plantations fermières dans les tropiques, 19-37.

Turnbull, J.W.

Ce volume est destiné à fournir un texte de référence pour tous ceux qui s'intéressent à la sélection et à la plantation d'arbres et arbustes dans les zones rurales des pays en développement et dans les régions tropicales d'Australie. Le premier chapitre souligne le caractère unique de la végétation australienne et de son évolution, et sa place comme élément typique de la flore mondiale.

L'originalité des végétaux ligneux d'Australie a été notée depuis l'époque de leur découverte et de leur étude par des botanistes européens. Dans quelle mesure sont-ils différents, c'est affaire d'interprétation, mais une de leurs originalités résulte du fait que quelque $75 \%$ des espèces sont endémiques de l'Australie, et que la végétation ligneuse sur la plus grande partie du continent est dominée par deux genres importants, Eucalyptus et Acacia. A un niveau taxonomique plus élevé, presque toutes les familles d'Angiospermes présentes en Australie se rencontrent communément dans d'autres parties du monde. Leurs caractéristiques particulières doivent être expliquées par la géographie et le milieu dans lequel elles ont évolué. 
L'isolement prolongé de l'Australie à la suite dela dislocation du supercontinent austral du Gondwana a grandement contribué au caractère distinctif de sa végétation. L'Australie a été isolée des autres continents pendant au moins 60 millions d'années. Durant cette période, de grands changements sont intervenus dans le climat et les sols, et ont joué un rôle important dans l'évolution de la flore moderne.

ACIAR Monograph No. 24, ACIAR, Canberra, Australie.

Acacia auriculiformis. In: Ibrahim, F.H.et van der Maesen, L.J.G. (sous la direction de) Espèces subsidiaires en agriculture et en plantations forestières, 52-6.

Turnbull, J.W. et Awang, K.

Données détaillées sur les usages, la botanique, l'écologie, la sylviculture, les ressources génétiques, la sélection, les perspectives et la littérature concernant Acacia auriculiformis.

PROSEA Handbook No. 11 Publications Backhuys, Lieden, Pays-Bas.

\section{Plantations forestières tropicales en vue de productions de haute valeur: étude de perspective du CIFOR.}

Turnbull, J.W. et Byron, R.N.

Les forêts naturelles ont fourni traditionnellement des bois de service et des bois d'œuvre, et des terres pour la mise en valeur agricole, mais on en attend maintenant une contribution à des objectifs plus larges, économiques, sociaux et écologiques. Là où le flux de bois et autres produits forestiers ne peut être alimenté de manière soutenue par les forêts naturelles, les plantations forestières et agroforestières peuvent fournir une grande partie de ces produits. Les perspectives de développement de la production de bois de valeur à partir de reboisements à petite échelle ou de plantations paysannes deviennent plus viables et plus attrayantes à mesure que s'accroît la pression démographique sur les ressources naturelles et que s'intensifie l'agriculture. Cependant, il se pose pour la recherche bien des questions nouvelles sur les techniques à appliquer, les orientations et les incitations économiques à adopter si l'on veut planter des arbres en plus petites parcelles, plus intégrées avec les autres utilisations du sol, et avec la participation directe de la population locale. Ce document décrit brièvement le programme de recherche du CIFOR en matière de 
plantations forestières, et met ensuite en lumière certains des problèmes qui se poseront pour la viabilité des plantations destinées à fournir des produits forestiers de plus grande valeur, plus particulièrement en ce qui concerne l'Indonésie. Un aperçu est donné des débouchés pour les bois feuillus provenant de reboisements dans la région Pacifique.

Exposé présenté à la Réunion consultative de l'ACIAR sur les priorités de recherche sur les produits forestiers de haute valeur autres que dediptérocarpacées en reboisements dans la région du Pacifique Sud-Ouest, Cairns, 6-8 mai.

Eucalyptus urophylla. In: Ibrahim, F.H.et van der Maesen, L.J.G. (sous la direction de) Espèces subsidiaires en agriculture et en plantations forestières, 140-4.

Turnbull, J.W. et Doran, J.C.

Informations détaillées sur les usages, la botanique, l'écologie, la sylviculture, les ressources génétiques, la sélection, les perspectives et la littérature concernant Eucalyptus urophylla.

PROSEA Handbook No. 11

Publications Backhuys, Lieden, Pays-Bas.

Changements et enjeux pour la foresterie internationale: préparer le 21ème siècle. In: Bachelard, E.P. et Brown, A.G. (sous la direction de) Préparer le 21ème siècle. Actes de la 4ème Conférence conjointe de l'Institute of Foresters of Australia et du New Zealand Institute of Forestry, 21-24 avril 1994, Canberra, 13-19.

Vanclay, J.K

Les changements récents, et ceux attendus, dans les techniques et dans les institutions, proposent de nouveaux défis aux forestiers d'Australie et d'ailleurs. S'accommoder du changement est facile lorsqu'il est prévu, mais lorsqu'il survient sans être annoncé ce sont ceux qui ont une large expérience et une connaissance actuelle qui y feront le mieux face. C'est pourquoi nous pouvons nous préparer au changement par des stages de recyclage bien choisis et en cherchant activement à élargir notre expérience. Il est probable que l'Australie jouera au plan régional et 
mondial un rôle accru dans l'avenir comme centre d'enseignement, réserve génétique et marché de bois. L'Australie et la Nouvelle-Zélande ont beaucoup de compétence et d'expérience dont nos voisins immédiats au nord pourront chercher à tirer profit, notamment en matière d'exploitation à faible impact, gestion de la recherche et planification de la conservation.

IFA, Canberra, Australie.

FLORES: un modèle pour évaluer les choix de mise en valeur des terres en lisière de forêt. Actes du colloque sur les progrès en matière de méthodologie et de logiciels pour les systèmes d'aide à la décision, 5-7 septembre 1997, Laxenburg, Autriche. Vanclay, J.K.

Les questions de politiques occupent une place centrale dans l'aménagement des ressources naturelles, mais les conséquences de politiques bien intentionnées ne sont pas toujours évidentes, surtout lorsqu'il s'agit d'utilisation des terres dans les zones forestières. Un modèle est proposé pour prédire le comportement des individus dans les communautés vivant en lisière de forêt et son incidence sur l'écosystème, et la réponse de celui-ci. L'hypothèse de base est que les individus agissent rationnellement pour un maximum d'avantage, et que l'on peut donc prédire leur comportement dans divers scénarios. Le modèle FLORES (Forest Land Oriented Resource Envisioning System - Système de prédiction pour les ressources des terres forestières) sera spatialement explicite, et permettra des tests empiriques solides. Initialement, le modèle testera des hypothèses proposées par des chercheurs associés, et aidera à reconnaître les lacunes et les déficiences dans les connaissances existantes. En définitive, il devrait aider les dirigeants et les planificateurs à mieux appréhender les conséquences de leurs propositions, et il pourra être utilisé comme jeu éducatif (cf Sim City, SimIsle, etc.).

http://www.iisa.ac.at/ marek/ftppub/Pubs/dss97/vanclay.pdf 
Tirer le maximum de profit des données de parcelles permanentes. In: Actes de la Conférence IUFRO 1.07/4.01/4.02.03 sur les études de croissance dans les forêts tropicales humides d'Afrique, 11-15 novembre 1996, Kumasi (Ghana), 43-8.

Vanclay, J.K.

L'auteur présente un catalogue d'idées pour l'analyse graphique des données sur la croissance, dans l'espoir de stimuler les analyses les plus imaginatives. Les graphiques peuvent être particulièrement révélateurs, parce que l'œil humain excelle à détecter des schémas. L'auteur présente des suggestions pour rendre les graphiques plus efficaces et les analyses plus pénétrantes.

IUFRO, Vienne, Autriche et CIFOR, Bogor, Indonésie.

Introduction à la prévision de rendement de la forêt. In: Méthodes de prévision de rendement des peuplements. Actes du colloque de Villefranche-sur-Mer, 24-27 octobre 1994. Eurostat, JRP-Ispra, DGVI et FAO, 265-71.

Vanclay, J.K.

Ce document présente les prévisions de croissance et de rendement de la forêt et leur place dans l'aménagement forestier et dans les politiques forestières. La gamme de biens et services fournis par les forêts, en outre du bois, est notée comme un facteur important dans ces modèles pour la formulation de prescriptions et d'orientations. L'auteur discute le rôle croissant des prévisions forestières dans les trois domaines des émissions d'origine anthropique, de la socio-économie et de l'écologie dans la mesure où elles se rapportent à l'aménagement et à la planification forestiers. Il présente des modèles de rendement des forêts artificielles et des modèles de croissance pour les forêts mélangées, ainsi que des suggestions d'autres termes et techniques de vérification pour réduire les problèmes d'interprétation.

ECSC-EC-EAEC, Luxembourg. 
Pour une évaluation plus rigoureuse de la biodiversité. In: Bachmann, P., Köhl, M. et Päivinen, R. (sous la direction de). Evaluation de la biodiversité en vue d'une meilleure planification forestière. Actes de la Conférence sur l'évaluation de la biodiversité en vue d'une meilleure planification forestière, 7-11 Octobre 1996, Monte Veritá, Suisse, 211-32.

Vanclay, J.K.

La biodiversité est souvent mal définie et étudiée de manière subjective, ce qui conduit à des estimations peu efficaces et ambiguës. Les atouts et les faiblesses des techniques d'étude en usage sont appréciés à partir de l'examen d'une bibliographie choisie. L'auteur utilise des analogies avec l'inventaire forestier pour suggérer des formules qui permettraient une évaluation plus efficace et plus rigoureuse de la biodiversité. Des techniques telles que les probabilités de variables et l'échantillonnage selon un modèle, notamment si elles sont utilisées conjointement avec une modélisation linéaire généralisée, offrent des substituts efficaces aux évaluations plus classiques à partir de quadrats et de parcelles emboîtées. Les méthodes de Bayes offrent des possibilités de combiner les connaissances scientifiques et locales avec des échantillons formels, et justifient une recherche plus poussée. Des suggestions de nouvelles recherches sont présentées.

Forestry Science Series 51, Kluwer, Dordrecht, Pays-Bas.

TROPIS, Système d'information sur la croissance des arbres et les parcelles permanentes. In: Actes de la Conférence IUFRO 1.07/4.01/4.02.03 sur les études de croissance dans les forêts tropicales humides d'Afrique, 11-15 novembre 1996, Kumasi, Ghana, 200-04.

Vanclay, J.K.

TROPIS, Système d'information sur la croissance des arbres et les parcelles permanentes, comprend cinq éléments: (1) un réseau de chercheurs désirant partager l'information sur les données de parcelles permanentes et la croissance des arbres (assuré par des bulletins et des sources d'information sur le site Error! Bookmark not defined. ou disponibles au CIFOR); (2) un répertoire ou une métabase de données de personnes et d'institutions détenant des données de parcelles permanentes; (3) un système de gestion de base de données (MIRA) pour aider à une 
gestion plus efficace des données; (4) un système (WORLD) pour identifier des sites comparables dans d'autres régions, permettant d'utiliser des données provenant d'ailleurs lorsqu'il n'existe pas d'information locale sur la croissance; un système de déduction (PLANTGRO) permettant de faire des estimations de croissance en l'absence de données empiriques. La plupart de ces éléments sont encore en cours d'élaboration, mais les deux premiers sont opérationnels. Le répertoire ou métabase de données contient actuellement des références de 10000 parcelles avec 2 000 essences fournies par une centaine de collaborateurs, et elle s'enrichit d'environ 1000 parcelles par mois. Les demandes de recherche dans la base de données sont bienvenues, et elles peuvent être adressées à l'auteur. IUFRO, Vienne, Autriche et CIFOR, Bogor, Indonésie.

\section{Evaluation des modèles de croissance des peuplements forestiers.}

Vanclay, J.K. et Skovsgaard, J.P.

Une évaluation efficace de modèles n'est pas une procédure simple et unique, mais comprend plusieurs étapes liées entre elles, qui ne peuvent être séparées l'une de l'autre ou dissociées de l'objet et du processus de construction du modèle. Nous attirons l'attention sur plusieurs procédures statistiques et graphiques qui peuvent aider à l'étalonnage et à l'évaluation du modèle, en insistant sur celles qui sont utiles pour la modélisation de la croissance des peuplements forestiers. Nous proposons un cadre en cinq étapes pour examiner la logique et la bio-logique, les propriétés statistiques, les caractéristiques des erreurs, les erreurs résiduelles, et les analyses de sensibilité. Des évaluations empiriques peuvent être faites avec les données utilisées dans l'ajustement du modèle, et avec des données supplémentaires non utilisées auparavant. Nous soulignons que la validité des conclusions tirées de toutes ces évaluations dépend de la validité des hypothèses de base faites tant pour le modèle que pour l'évaluation. Ces principes doivent être gardés présents à l'esprit tout au long de la construction et de l'évaluation du modèle.

Ecological Modelling 96: 1-12. 
Utilisation des attributs fonctionnels des plantes pour l'évaluation de la productivité de la station et des modes de croissance dans les forêts mélangées.

Vanclay, J.K., Gillison, A.N. et Keenan, R.N.

Les modèles de croissance des peuplements forestiers se rangent parmi les préalables importants de l'aménagement forestier. La complexité des forêts tropicales mélangées fait que l'on a souvent peu d'information objective pour classer les stations et les essences en vue d'établir des modèles de croissance et des prédictions de rendement. Une classification fondée sur des caractères morphologiques observables peut être un substitut ou un complément utile à d'autres méthodes. Les auteurs ont étudié l'utilité d'attributs fonctionnels des plantes (PFA) pour la classification des stations et des essences. Les attrributs fonctionnels des plantes décrivent la plante en fonction de son système photosynthétique et vasculaire, et la somme des PFA individuels pour toutes les espèces d'une parcelle fournit un résumé valable des caractéristiques des caractéristiques de la végétation sur la station. Des observations préliminaires indiquent que ce résumé des PFA pourrait aussi donner une indication sur la productivité de la station, et que des PFA spécifiques pourraient être utilisés pour regrouper les espèces en vue de modéliser la croissance et le rendement. Des données provenant de 17 parcelles permanentes dans les forêts denses tropicales du Nord Queensland ont été utilisées pour tester ces observations préliminaires. Des fiches normalisées de PFA ont été établies pour chaque parcelle en janvier 1995, et les relations entre les PFA, la productivité de la station et les modes spécifiques de croissance ont été étudiées par analyse discriminante, régression linéaire et tests statistiques normaux. Les résultats indiquent que la taille moyenne des feuilles, et la présence d'essences ayant une inclinaison verticale des feuilles (plus de $30^{\circ}$ au-dessus de l'horizontale) sont en corrélation significative avec la productivité de la station. Sur tous les PFA évalués, cinq éléments s'avèrent fournir une base utile pour grouper les espèces en vue de la modélisation: taille et inclinaison des feuilles, indice de "fourchaison" (hauteur relative de la première fourche ou de la première rupture de continuité de la tige principale), et présence de lenticelles et de tissu chlorophyllien sur la tige principale. La nature limitée de notre base de données interdit un jugement général sur l'utilité de la méthode, mais les résultats semblent justifier une poursuite du travail sur les PFA. 
Chasse des primates et aménagement forestier: le cas des agriculteurs forestiers Iban au Kalimantan Oriental, Indonésie. Waldley, R.L., Colfer, C.J. Pierce et Hood, I.G.

La chasse est pour les agriculteurs forestiers Iban du Kalimantan Timur (Indonésie) un élément important de leur économie de subsistance, et à ce titre elle fait l'objet d'une étude dans le cadre d'un projet de conservation dans la Réserve de faune de Danau Sentarum. Nous examinons dans cet article la chasse de primates par les Iban, en comparaison de celle des autres grands mammifères. Nous analysons les taux de rencontre et de capture, en comparant les rencontres, les expéditions de chasse, et les nombres d'animaux. L'information sur les habitats chassés montre l'importance des forêts secondaires et des forêts âgées. Nous examinons également les attitudes des Iban, leurs préférences en matière de gibier, et leurs tabous. L'importance de ces résultats est discutée au regard des menaces pour le gibier dues à la multiplication des armes à feu, à la population humaine et à la destruction des habitats, en montrant qu'on peut aider à la conservation en encourageant ou en améliorant certains aspects du système agroforestier traditionnel des Iban.

Human Ecology 25: 243-71.

Mécanismes du déboisement: résultats d'une enquête. Wibowo, D.H. et Byron, R.N.

Les auteurs examinent de nombreux modèles publiés de déboisement dans les tropiques, classés en quatre catégories:

- Une approche néo-malthusienne, souvent nébuleuse et imprécise en ce qui concerne les processus causals, qui considère la pression démographique comme la cause fondamentale du déboisement dans les tropiques;

- Celles axées sur des carences de l'Etat - en particulier des politiques mal orientées dans d'autres secteurs, conduisant à un déboisement excessif et inopportun, des politiques sectorielles (par exemple interdiction de l'exportation de grumes), et une défaillance générale des institutions étatiques chargées du contrôle, notamment corruption. Cette approche fait une large place aux effets des interventions étatiques;

- Une approche microéconomique, qui considère la rationalité économique du défrichement des forêts du point de vue des agriculteurs, 
et explique comment diverses formes de défauts des marchés, par exemple des droits de propriété mal définis, des contrats d'exploitation forestière mal rédigés et une sous-évaluation des bénéfices de la forêt au niveau local, régional ou mondial, contribuent tous au déboisement;

- Une approche mettant l'accent sur la macroéconomie, qui explore les liens supposés entre dette et déboisement, conduisant à l'échange dettenature comme moyen de réduire le taux de déboisement dans les pays en développement.

Les auteurs concluent que les carences des gouvernements et les analyses microéconomiques sont particulièrement appropriés pour comprendre les processus actuels de déboisement et les choix d'orientations en Indonésie.

Working Paper No. 19: Economics, Ecology and the Environment Programme, University of Queensland, Brisbane, Australie. 32p.

Déboisement et accumulation de capital: leçons tirées de la région du Haut Kerinci, Indonésie. Wibowo, D.H. et Byron, R.N. Wibowo, D.H., Tisdell, C.A. et Byron, R.N.

Cette étude examine un cas dans lequel c'est le comportement des agriculteurs qui accumulent du capital, plutôt que leur pauvreté comme on l'admet communément, qui est la cause du déboisement. Une étude de terrain a été entreprise dans la région du Haut Kerinci, île de Sumatra (Indonésie). Une analyse financière des flux de "revenus nets" obtenus par les agriculteurs du déboisement est effectuée. En effet les terres boisées peuvent être accaparées et privatisées par le défrichement suivi de mise en culture, ce qui procure aux agriculteurs des profits financiers importants tout en leur fournissant un capital suffisant pour financer les prochains défrichements. Une telle capacité permet à des paysans sans terre de devenir propriétaires fonciers. Le défrichement des forêts leur permet aussi d'avoir un placement à long terme sous la forme d'une plantation de canneliers. La pauvreté empêche les paysans les plus démunis de déboiser, et la décision de défricher une forêt est surtout le fait des agriculteurs mieux pourvus. Les surplus financiers provenant de secteurs autres que forestier et agricole servent aussi à financer le défrichement de la forêt.

Working Paper No. 8: Economics, Ecology and the Environment Programme, University of Queensland, Brisbane, Australie. 19p. 
Prise de décisions entre intérêts divers: emploi de scénarios d'avenir pour orienter la gestion locale des forêts - proposition de méthodologie. Exposé présenté au Séminaire sur la foresterie communautaire à un carrefour: réflexions et orientations futures en matière de développement forestier communautaire, 17-19 juillet 1997.

Wollenberg, $E$.

Ce document propose une méthodologie en vue d'améliorer le processus de décision dans la gestion locale des forêts, définie ici comme la participation des riverains d'une forêt aux activités destinées à conserver ou améliorer la forêt tout en accroissant le bien-être de la population locale. La méthode permet aux diverses parties prenantes d'identifier collectivement leurs besoins futurs et la politique appropriée pour y répondre, grâce à l'élaboration de scénarios d'avenir. Cette méthode met davantage l'accent sur le processus d'élaboration de tels scénarios par consultation des intéressés que sur le produit des scénarios ou les modèles utilisés pour les produire.

Bangkok, Thaïlande, Centre régional de formation en foresterie communautaire (RECOFTC). $9 p$

Stabilité sociale. In: Borrini-Feyerabend, G. et Buchan, D. (sous la direction de) Au delà des barrières: recherche de la stabilité sociale dans la conservation. Volume 2, 115-17.

Wollenberg, E. et Colfer, C.J.P.

Dans les discussions sur les problèmes et les dilemmes de la conservation, on entend couramment le terme de "stabilité sociale" ou des mentions des "aspects sociaux de la stabilité". Bien que ces concepts soient souvent utilisés, ils sont rarement définis. Les auteurs proposent trois définitions qui peuvent être utilisées séparément ou en combinaison. La stabilité sociale peut être définie comme le maintien du bien-être de la population (notamment la partie de celle-ci qui est le plus tributaire des ressources en jeu), comme les actions de la population visant à conserver ces ressources, ou comme le maintien de bénéfices équitables d'une génération à l'autre. Il faut être clair sur la définition que l'on utilise pour avoir une compréhension mutuelle de ce que l'on cherche à réaliser par la stabilité sociale. 
Les auteurs soulignent que toute définition de la stabilité est par nature relative, et liée aux limites de temps, de lieu et de population considérée. Dans toute situation, il importe de maintenir la souplesse dans la vision que l'on a de la stabilité sociale, et être prêt à modifier cette vision en fonction de circonstances changeantes ou différentes.

UICN, Gland, Suisse.

\section{Morcellement des forêts et biodiversité: arguments en faveur d'aires de conservation de taille intermédiaire.}

Zuidema, P.A., Sayer, A.J. et Dijkman, W.

Il est essentiel de connaître les effets du morcellement des forêts sur la biodiversité si l'on veut assurer une conservation efficace des forêts. Quatre facteurs peuvent intervenir pour entraîner une perte de biodiversité dans les forêts morcelées: l'effet d'un échantillonnage non aléatoire de la forêt originelle, une taille de forêt réduite, l'isolement, et les effets de bordure. Un examen de 58 études sur les effets du morcellement des forêts révèle que les conclusions générales tirées des recherches sur le morcellement sont biaisées du fait qu'elles sont centrées sur la faune aviaire, sur les effets de la taille plutôt que de l'isolement, et sur la présence des espèces plutôt que sur la taille de leurs populations. La conclusion la plus importante est sans doute que les connaissances actuelles sur les effets du morcellement s'appuient principalement sur l'étude de petits fragments ou relictes de forêt $(<10 \mathrm{ha})$. Les effets de bordure prédominent dans celles-ci, pour de nombreuses espèces elles ne peuvent pas abriter des populations viables, et elles font rarement l'objet de programmes de conservation. L'étude de relictes de faible étendue ne peut pas être extrapolée à des aires de conservation de plus grande taille. Des aires de conservation de taille moyenne, stratégiquement situées sont sans doute une formule plus efficace pour la conservation de la biodiversité, compte tenu des limitations financières, sociales et logistiques. Il faudrait davantage de recherches sur l'aménagement forestier qui soient représentatives des tailles d'aires protégées réellement existantes (à savoir > $10000-100000$ ha), et elles devraient s'intéresser spécialement aux processus biologiques et anthropiques qui déterminent la persistance des espèces.

Environmental Conservation 23(4): 290-297, 1996. 
Pour commander des publications du CIFOR, veuillez contacter:

Communications Unit

CIFOR

P.O. Box 6596 JKPWB

Jakarta 10065

Indonésie

Tél.: + 62 (251) 622622

Fax: + $62(251) 622100$

e-mail: cifor@cgiar.org

Pour commander des publications payantes, veuillez envoyer les renseignements sur votre carte de crédit (nom du titulaire, numéro de la carte, date d'expiration et signature). Nous n'acceptons que les cartes Visa et Master Card. 